NASA Technical Memorandum 106244

AIAA-93-1898

Performance of a Low-Power Subsonic-Arc-Attachment Arcjet Thruster

John M. Sankovic

Lewis Research Center

Cleveland, Ohio

and

Darren H. Berns

University of Minnesota

Minneapolis, Minnesota

Prepared for the

29th Joint Propulsion Conference and Exhibit cosponsored by the AIAA, SAE, ASME, and ASEE Monterey, California, June 28-30, 1993 


\title{
PERFORMANCE OF A LOW-POWER SUBSONIC-ARC-ATTACHMENT ARCJET THRUSTER
}

\author{
John M. Sankovic* \\ National Aeronautics and Space Administration \\ Lewis Research Center \\ Cleveland, $\mathrm{OH} 44135$
}

and

\author{
Darren H. Berns ${ }^{* *}$ \\ University of Minnesota \\ Minneapolis, MN 55455
}

\begin{abstract}
$\underline{\text { Abstract }}$
A subsonic-arc-attachment thruster design was scaled from a $30 \mathrm{~kW} 1960$ 's vintage thruster to operate at nominally $3 \mathrm{~kW}$. Performance measurements were obtained over a $1-4 \mathrm{~kW}$ power range using hydrogen as the propellant. Several modes of operation were identified and were characterized by varying degrees of voltage instability. A stability map was developed showing that the voltage oscillations were brought upon by elevated current or propellant levels. At a given specific energy level the specific impulse increased asymptotically with increased flow rates. Comparisions of performance were made between radial and tangential propellant injection. When the vortex flow was eliminated using radial injection, the operating voltages were lower at a given current, and the specific impulse and efficiency decreased. Tests were also conducted to determine the effects of background pressure on operation, and performance data were obtained at pressures of $0.047 \mathrm{~Pa}$ and $18 \mathrm{~Pa}$. For a given specific energy level, the performance increased with a decrease in facility background pressure. Lowering the background pressure also caused a dramatic change in the voltage-current characteristic and the voltage stability, a phenomenon not previously reported with conventional supersonic-arc-attachment thrusters.
\end{abstract}

\section{Introduction}

The research and technology development effort in the 1960's resulted in two different endurancetested, high-power, hydrogen arcjet designs for orbit transfer applications. One of the designs was developed by Avco Corp. and completed a voluntarily-terminated $723 \mathrm{~h}$ endurance test at 30
$\mathrm{kW}$ with a specific impulse of $1010 \mathrm{~s}$ and an efficiency of 0.41 . The Avco anode/nozzle design was very similar to current state-of-the-art low-power hydrazine arcjets with supersonic-arcattachment. It consisted of a conical converging entrance, a constant area constrictor, and a conical diverging exit 1 . The second $30 \mathrm{~kW}$ hydrogen arcjet design was developed by Giannini Scientific Corp. (GSC). That regenerativelycooled engine, incorporating subsonic-arcattachment, completed a voluntarily terminated $500 \mathrm{~h}$ endurance test with a specific impulse of $1000 \mathrm{~s}$ and an efficiency of $0.55^{2}$. The GSC nozzle design was much different than those used currently. It consisted of a long cylindrical section upstream of a conical DeLaval nozzle. Although both programs demonstrated life at the respective program performance goal, the highpower arcjet effort was cancelled due to the lack of a space power source. The results of the early hydrogen arcjet development effort are summarized by Sankovic, et al. ${ }^{3}$.

Recently, interest has again developed regarding the use of high-power arcjets for orbit transfer. The Air Force is proceeding with flight experiments using ammonia as the propellant. Under the Advanced Technology Transition Demonstration (ATTD) program, a $26 \mathrm{~kW}$ arcjet system is being developed and flight qualified. Once qualification is complete the unit will be flight-tested in the Electric Propulsion Space Experiment (ESEX) set for launch in 1995. The Air Force is currently defining the Electric Insertion Transfer Experiment (ELITE) as a precursor to an operational electric orbit transfer vehicle ${ }^{4}$. In support of these efforts the Jet Propulsion Laboratory (JPL) has completed a $1460 \mathrm{~h}$ endurance test at $10 \mathrm{~kW}$ on ammonia 5 .

\footnotetext{
*Aerospace Engineer, On-Board Propulsion Branch, Member AIAA

** Graduate Student, Department of Mechanical Engineering

Copyright (c) 1993 by the American Institute of Aeronautics and Astronautics, Inc. No copyright is asserted in the United States under Title 17, U.S. Code. The U.S. Government has royalty-free license to exercise all rights under the copyright claimed herein for Governmental purposes. All other rights are reserved by the copyright owner.
} 
Because of the higher specific impulse hydrogen arcjets offer over other propellants, the SDIO Office of Innovative Science and Technology and the NASA Office of Advanced Concepts and Technology have sponsored programs over the past several years to determine the viability of 10 $\mathrm{kW}$ class hydrogen arcjets for orbit transfer applications. Under those programs, performance measurements have been obtained on a laboratory model high-power hydrogen arcjet 6 , and a $10 \mathrm{~kW}$ power processing unit has been developed and integrated with a thruster 7 . Most of the current technology effort in high-power arcjets has concentrated on a thruster design similar to the 1960 's Avco thrusters.

The high efficiency of the GSC device is of great interest and is unmatched by current technology. The higher efficiency values reported for the GSC device have been attributed to regenerative preheating of the incoming propellant combined with lower frozen flow losses due to recombination in the high pressure subsonic-arcattachment zone. It has been shown through segmented-anode work on low-power thrusters 8 , utilizing conventional anodes of the Avco type, that the anode arc attachment is in the low pressure supersonic divergent section of the nozzle. The low pressure heat addition in the conventional designs may increase frozen flow losses by hindering recombination. Under a SDIO sponsored effort, Rocket Research Co. geometrically scaled the $30 \mathrm{~kW}$ Giannini design to $10 \mathrm{~kW}$ and obtained performance measurements. The efficiency levels up to $950 \mathrm{~s}$ specific impulse were considerably higher than conventional designs but dropped off rapidly as specific impulse was increased. In general the performance was lower than expected from the data reported by GSC ${ }^{9}$. To determine if the loss of performance was due to a scaling phenomenon, a duplicate of the $30 \mathrm{~kW}$ regenerative thruster was fabricated and tested at NASA LeRC. The results showed the efficiency of the thruster to be impressive, but to still fall short of the efficiencies reported by GSC 10 .

Because of the lack of data and the ability to investigate the effects of facility pressure on performance, it was decided to investigate the operation of a subsonic-arc-attachment thruster at low powers. A nominal $3 \mathrm{~kW}$ anode geometry was scaled down from the GSC work and designed to operate with a laboratory-model, modular arcjet thruster. Data were obtained and are reported for power levels ranging from 0.5 to 4 kilowatts at various hydrogen propellant flow rates. High frequency arc instabilities which were current and flow rate dependent were identified. In order to quantify the instability phenomenon and to determine if the arc attachment was indeed in the subsonic zone, a segmented-anode version of the thruster was designed and tested. The results of the segmented-anode work are reported in a companion paper ${ }^{11}$.

\section{Experimental Apparatus}

\section{Arcjet Thruster}

The arcjet thruster assembly used was a modular, low-power design, developed at NASA LeRC and used in previous testing 12 . A schematic of the thruster is presented in Figure 1 and detail of the electrode region is provided in Figure 2. The anode geometry was scaled from the endurancetested, regeneratively-cooled $30 \mathrm{~kW}$ GSC design to run at nominally three kilowatts. A comparision of the nozzle dimensions for the two devices are given in Table I. The upstream side converged conically at a $30^{\circ}$ angle from $0.64 \mathrm{~cm}$ to the arc chamber diameter of $0.25 \mathrm{~cm}$. The arc chamber was cylindrical with a length of 0.91 $\mathrm{cm}$. The cylindrical arc chamber is a slight deviation from the regeneratively-cooled GSC design which incorporated a slightly narrower diameter throat upstream of the arc chamber. That feature was omitted in this design to ease the fabrication of the anode. Downstream of the arc chamber the nozzle converged to a $0.15 \mathrm{~cm}$ diameter throat. The divergent end of the nozzle was conical and had a half angle of $15^{\circ}$ and an area ratio of 39 . The arcjet was designed to operate radiation-cooled, and no attempt was made to regeneratively preheat the incoming propellant. Both the anode and the cathode were fabricated from two-percent thoriated tungsten. The cathode was $0.32 \mathrm{~cm}$ in diameter with a $30^{\circ}$ half angle conical tip. The front insulator was fabricated from high purity boron nitride, while the rear insulator was made from boron nitride containing a calcium oxide binder. Propellant was injected tangentially through two $0.051 \mathrm{~cm}$ diameter holes perpendicular to the cathode in order to form a vortex in the flow. To determine the effects of propellant injection on performance, some data were taken with radial, instead of the typical tangential, injection. Radial injection was provided by removing the gas injection disk, and cutting radial slots in the front face of the insulator. Propellant sealing was provided by graphite foil gaskets. The arc gap was set by retracting the cathode $0.058 \mathrm{~cm}$ from contact with the anode. 
Facility

Power processing was provided by a $5 \mathrm{~kW}$ output dc-dc converter operated as a constant current supply incorporating a pulse starting circuit described by Gruber, et al.13. All performance data were taken using the displacement-type thrust stand developed by Haag and described in Ref. 14. Calibration was performed in-situ under vacuum by loading the thrust stand with calibrated weights before and after test runs. The thrust stand design incorporated a water-cooled housing to limit thermal effects on the measurements, and accuracy was estimated to be within $1 \%$. The thrust stand was contained in a 1.5 diameter, $5 \mathrm{~m}$ long vacuum chamber pumped by four $0.82 \mathrm{~m}$ oil diffusion pumps, each with a rated capacity of approximately $32 \mathrm{~m}^{3} / \mathrm{s}$ at 0.19 $\mathrm{Pa}$. The diffusion pumps were backed by a 0.61 $\mathrm{m}^{3} / \mathrm{s}$ rotary blower and two $0.14 \mathrm{~m} 3 / \mathrm{s}$ roughing pumps. The diffusion pumps were not used for some of the tests since the propellant flow rates exceeded the rated capacity. At $10 \mathrm{mg} / \mathrm{s}$ hydrogen flow rate the facility pressure with the diffusion pumps on was $0.047 \mathrm{~Pa}$ and with the diffusion pumps off was $18 \mathrm{~Pa}$. At the higher flow rates of $20 \mathrm{mg} / \mathrm{s}, 30 \mathrm{mg} / \mathrm{s}$, and $42 \mathrm{mg} / \mathrm{s}$ all data reported were taken without the diffusion pumps and the facility pressures were $45 \mathrm{~Pa}, 60 \mathrm{~Pa}$, and $89 \mathrm{~Pa}$, respectively.

\section{Instrumentation and Calibration}

A microcomputer-based data acquisition system (DACS) was used to record performance data and is described in Ref. 15. The computer monitored propellant flow rate, current, voltage, thrust, thruster temperature, and propellant feed pressure. The data acquisition system measured current using a calibrated shunt. In addition to the DACS, a digital oscilloscope was used to monitor arc current and voltage. Arcjet current information to the oscilloscope was provided from a Hall-type sensor calibrated on a dc-source prior to each run. The voltage measurements were taken at the power connector feedthrough on the vacuum facility. The propellant flow rates were measured using a 0-30 and a 0-10 SLPM thermal-conductivity type flow controller. The flow controller was calibrated in-situ using a constant volume technique. Flow measurement accuracy was estimated at $1 \%$. Facility pressures were measured using uncorrected ionization gauges calibrated on air at low pressures and capacitance manometers at high pressures. Temperatures were measured with a two-color pyrometer with a range of $1700-3500^{\circ} \mathrm{C}$ through quartz windows.

\section{Experimental Procedure}

The arcjet was assembled with a cathode which had previously been burned-in for several hours. This was done to maintain repeatability in the data from the initial start-up to other operating runs. The arcjet was started on hydrogen, but experienced some starting difficulty at the higher propellant flow rates. Upon start-up, high frequency voltage oscillations occured even at the lowest flow rates, but as the thruster heated up, the oscillations subsided. The existence of high voltage fluctuations upon ignition may have contributed to starting problems by exceeding the open circuit voltage on the power processing unit (PPU). Once started, the thruster was allowed to operated for at least twenty minutes before data were taken, in order to achieve thermal equilibrium. In fact, the thruster operating conditions stabilized much more rapidly. Variations in the operating temperature and thrust due to incremental changes in the current and flow rate came to equilibrium in matter of minutes, and data were taken five to ten minutes after an incremental change in operating condition. Repeatability of the data was established by duplicating selected points during a run and after disassembly and reassembly.

The lowest operating current levels were limited by the open circuit voltage levels of the PPU, while the highest current levels were set by a $2000{ }^{\circ} \mathrm{C}$ anode temperature limit. Likewise, the maximum propellant flow rate was limited to the pumping capacity of the facility with the diffusion pumps on and by the PPU open circuit voltage with the diffusion pumps off. The minimum propellant flow rate was also controlled by the $2000{ }^{\circ} \mathrm{C}$ anode temperature limit.

\section{$\underline{\text { Results and Discussion }}$}

The first set of data obtained were at high facility background pressures and included tangential injection of the propellant. The data from this baseline set of runs are included in Table II. The operation of the arcjet was very dependent on the propellant flow conditions and the current levels, as presented in the stability map of Figure 3. Two areas are devoid of data. The first is the area of low current operation at high flow rates where the voltage rises exponentially, and data were not obtained due to the upper voltage limitation of the power processor. The second area consists of very low flow rate operation and is a regime damaging to the thruster. The 
section for which data were obtained shows a small stable region, a region of transition to restrike, and a continuous restrike region.

The different modes of operation are illustrated in Figure 4 which takes a constant flow rate path across the stability map of Figure 3, using a flow rate of $10 \mathrm{mg} / \mathrm{s}$. The stable region, consisting of low flow rates and low currents, is characterized by a steady operating voltage. The oscilloscope photograph taken at $6 \mathrm{~A}$ discharge current presented in Figure 4a is characteristic of this region. For a constant propellant flow rate, as the current is increased, the average arc voltage decreases but shows no sign of high frequency oscillations. This is typical for a negative voltage-current characteristic and is illustrated by Figure $4 \mathrm{~b}$. As the current is increased further, another operating mode develops and defines the left border between the stability and transition regions. This new mode is characterized by drops in the voltage along sections of voltage trace at a frequency of approximately $200 \mathrm{kHz}$. The mode is very unstable as is noted in Figure 4c, and the tendency is to jump back suddenly into a stable mode, shown in Figure 4d. The instability is similar to that identified by Curran et al. occuring in low-power hydrogen arcjets with a conventional supersonic-arc-attachment 16 . The phenomenon was also reported in Reference 17 at power levels of twenty to thirty kilowatts with nitrogen and hydrogen, but the voltage oscillations did not occur with helium or argon. Reference 17 suggested that one cause for the oscillations was the movement of the arc anode attachment point. Berns and Sankovic 11 using a segmented-anode arcjet demonstrated that the high frequency drop in voltage is indeed a restrike phenomenon caused by a movement of the anode attachment point of the arc to a region upstream. Figure $4 \mathrm{e}$ shows that as one moves to the right through the transition region and the current increases to $14 \mathrm{~A}$, the amplitude of the voltage instablity increases as does its duration; although, episodes without oscillations, as shown in Figure 4f, exist sporadically. As the current is yet increased further to $16 \mathrm{~A}$, another operating mode is uncovered. The voltage is steady on a millisecond time scale but steadily increases by over $20 \mathrm{~V}$ over a duration of approximately a second, then suddenly the arc enters restrike. It remains in restrike for a few seconds then quickly jumps down to the lower steady voltage, and the cycle is repeated. Oscilloscope photographs in Figures $4 \mathrm{~g}, 4 \mathrm{~h}$, and $4 \mathrm{i}$ help to illustrate the phenomena. Figures $4 \mathrm{j}$, $4 \mathrm{k}$, and $4 \mathrm{l}$, demonstrate that incrementally increasing the current further to $18 \mathrm{~A}$ causes the restrike to occur during the voltage rise cycle, not when the voltage has reached its maximum value. Eventually, at a high enough current the restrike becomes constant as the continuous restrike region is entered.

At a constant current, it was found that increasing the flow rate also brings about restrike. Starting in the transition zone at 10 $\mathrm{mg} / \mathrm{s}$ and $14 \mathrm{~A}$, the onset of restrike again is noted by the development of regions on the voltage trace characterized by high frequency voltage drops, as is shown in Figure 5a, and then sudden steady operation of Figure $5 \mathrm{~b}$. The oscilloscope trace in Figure 5c was taken at 20 $\mathrm{mg} / \mathrm{s}$ and shows operation in complete restrike. As the flow rate is increased further to $30 \mathrm{mg} / \mathrm{s}$, the restrike mode continues to be the only operating mode, and the amplitude of the oscillations increases as is illustrated in Figure $5 d$.

A voltage-current (V-I) characteristic of the data from Table II is plotted in Figure 6. The voltage values reported are from the computer data acquisition system. The effect of restrike on the DACS was investigated by comparing the values reported by the DACS to the average voltage determined manually from the oscilloscope. The results compared to within \pm 2 V. The V-I data for operation at $10 \mathrm{mg} / \mathrm{s}$ is quite scattered due to operation in the transition region were the voltage at any given instant can vary significantly. Data obtained at the higher flow rates were more repeatable and were obtained at operating conditions of continuous restrike. It is important to remember that the voltages reported in Table II and in Figure 6 are averages. The peak voltages, especially at flow rates of 20 $\mathrm{mg} / \mathrm{s}$ and above, where operation is in the continuous restrike region, were much greater.

Figure 6 shows clearly that the static impedance of the arcjet is negative. Examination of the oscilloscope traces taken while the arcjet was not operating in restrike show that the dynamic impedance is positive. Figures $4 \mathrm{a}, 4 \mathrm{~b}$, and $5 \mathrm{~b}$ show that as the current increases due to PPU ripple, the voltage also increases. Hamley 18 conducted an investigation of the effects of current ripple on the static and dynamic impedances of a low-power arcjet run on nitrogen/hydrogen mixtures. That study found that the dynamic impedance phase angle shifted significantly with ripple frequency, especially at frequencies greater than $10 \mathrm{kHz}$, for supersonicarc-attachment thrusters. The work has not been repeated using pure hydrogen, and no data have 
been obtained for an arcjet with subsonic-arcattachment; therefore, it is not known at what ripple frequency a phase shift begins to occur.

Figures 7 and 8 are plots of specific impulse versus specific energy and efficiency versus specific impulse, respectively. At a given specific energy the specific impulse increases dramatically with an increase in flow rate up to $30 \mathrm{mg} / \mathrm{s}$. For example, at a specific energy of 80 $\mathrm{MJ} / \mathrm{kg}$, the difference in specific impulse between mass flow rates of $10 \mathrm{mg} / \mathrm{s}$ and $20 \mathrm{mg} / \mathrm{s}$ is near $100 \mathrm{~s}$, while the difference reduces to $20 \mathrm{~s}$ between flows rate of $30 \mathrm{mg} / \mathrm{s}$ and $42 \mathrm{mg} / \mathrm{s}$. Beyond that point any increase in flow rate causes only a very slight increase in performance. It was suspected during this study, and later proved by Berns and Sankovic11, that at the lower flow rates the arc attachment point was in the upstream area of the cylindrical section of the nozzle and as the flow rate increased the arc attachment point moved downstream, but still remained in the cylindrical section. One explanation for the difference in performance is the fact that some energy added by the arc is lost to the walls before expansion occurs. As the flow rate is increased the arc attachment point is moved downstream, closer to the throat, and expansion takes place sooner with less anode losses causing a higher efficiency.

The effect of propellant injection on performance was also investigated in this study. The injection was changed from tangential to radial which eliminated the vortex. Performance data for that operating condition are included in Table III. The V-I plots provided in Figure 9 show that at a given flow rate the operating voltage is lower without vortex injection. The magnitude of the voltage difference between the two propellant injection techniques and the scatter in the data increase as the flow rate is decreased, as clearly demonstrated by the $20 \mathrm{mg} / \mathrm{s}$ data. Figure $10 \mathrm{a}$ and $10 \mathrm{~b}$ are oscilloscope traces taken at $20 \mathrm{mg} / \mathrm{s}$ and $16 \mathrm{~A}$ showing that eliminating the vortex causes not only a decrease in the average voltage but a cleaner trace. Figures $11 \mathrm{a}$ and $11 \mathrm{~b}$ are similar photographs taken at a different operating condition of $30 \mathrm{mg} / \mathrm{s}$ and 14A. They show that at high flow rates when operation is in the steady restrike region of Figure 3, the lack of vortex injection causes a decrease in the peak-to-peak amplitude of the high frequency voltage oscillations, along with a slight decrease in the average voltage. The effects of vortex injection on the specific impulse are compared in Figure 12. The $20 \mathrm{mg} / \mathrm{s}$ data show a slight decrease in specific impulse with radial injection. The effect is most pronounced at the higher flow rate of $30 \mathrm{mg} / \mathrm{s}$ where the difference is between $50 \mathrm{~s}$ and $75 \mathrm{~s}$. A corresponding effect is also noted in the efficiency versus specific impulse plot in Figure 13. The effect of propellant injection on performance is most likely due to changes in the arc attachment region as is inferred from the different operating voltages.

The final segment of this study investigated the effects of facility pressure on performance. Due to the limitation of the vacuum facility, high pumping speeds could only be maintained at flow rates of $10 \mathrm{mg} / \mathrm{s}$ and below. Performance data were obtained at facility pressures of $18 \mathrm{~Pa}$ and $0.047 \mathrm{~Pa}$. Data obtained at the higher pressure are contained in Table II while those obtained at the lower pressure are given in Table IV. A plot of the V-I characteristic at each of those pressures is provided in Figure 14. The facility pressure clearly has an effect on the voltage of the subsonic-arc-attachment thruster, a phenomenon not seen with supersonic-arc-attachment arcjets 16,19 . The voltage is an average $20 \mathrm{~V}$ higher at the lower facility pressure, and the scatter is reduced. As the pressure is reduced the arc stability increases. At the low background pressure and at low current levels the voltage is generally stable with no restrike but is subject to sporadic drops in voltage of between $20-30 \mathrm{~V}$ and the onset of restrike at the lower voltage level. When the voltage jumps back to the original level, the restrike disappears. As the current level is increased the voltage drops occur more often. From Ref. 11 it is clear that the arc attachment is in the subsonic upstream cylindrical region, and intuitively one would expect the arc physics to be isolated from downstream effects. To investigate the phenomenon further pressure taps were placed in the the cylindrical arc-attachment region and measurements were obtained at various facility background pressures. The methodology and results are provided in Reference 11. Figures 14 and 15 present the effect of facility pressure on specific impulse and efficiency. At a given specific energy level the specific impulse is greater at lower pressures, but the data contain more scatter. Likewise, the efficiency at a given specific impulse is slightly increased. The difference in performance is not accounted for by a simple pressure-area correction which at $18 \mathrm{~Pa}$ facility background pressure amounts to a thrust correction of only $1.6 \mathrm{mN}$. This is similar to the effect noted by Sankovic and Curran 19 for supersonic-arc-attachment arcjets and attributed to differences in anode losses. 
An attempt was made to compare the performance of the subsonic-arc-attachment arcjet to conventional supersonic designs. Reference 19 provides data taken on hydrogen at similar facility background pressures and propellant flow rates obtained using an arcjet with a conventional nozzle design. The nozzle geometry consisted of a conical converging section with a $30^{\circ}$ half angle, a $0.064 \mathrm{~cm}$ diameter and $0.025 \mathrm{~cm}$ long constrictor, and a conical diverging section with a $20^{\circ}$ half angle and an area ratio of 225 . The facility pressure was $20 \mathrm{~Pa}$ and $45 \mathrm{~Pa}$ at propellant flow rates of $10 \mathrm{mg} / \mathrm{s}$ and $22.5 \mathrm{mg} / \mathrm{s}$, respectively. The data used for comparision from this study were taken from Table II. A comparison of the specific impulse and efficiency between the two designs is provided in Figures 17 and 18. The plots show that the performance is significantly greater for the conventional design. The reader is cautioned not to draw far reaching conclusions from the two figures. The performance data obtained in this study used an arcjet geometry which has not been subjected to extensive optimization for performance. The effects of electrode geometrical changes on performance of a subsonic-arc-attachment thruster is unknown. The area ratio of the nozzle in this study was 39 while that used in Ref. 19 was 225. It is assumed from the work done by Curran, et al. 20 that increasing the area ratio would increase the performance significantly. It has also been demonstrated that propellant injection has a strong effect on the performance of this device, and the optimum propellant injection scheme has not been determined. Finally, the facility pressure has been shown to have a major effect on the performance of both types of devices. It is not clear whether the effect on specific impulse and efficiency is the same for both thrusters, since the V-I characteristics are clearly affected differently.

The two devices also operated very differently. For the majority of test points no plume was visible with the subsonic-arc-attachment arcjet. It was only at the highest flow rates that a narrow blue "tongue" appeared from the nozzle exit. This was unlike the conventional design which had a diffuse plume. Both types of thrusters when operated on hydrogen experienced voltage instabilites. Curran, et al.16 identified the occurance of restrike in $1-4 \mathrm{~kW}$ conventional design thrusters; however, the frequency of those oscillations was 1-2 $\mathrm{MHz}$ which was much higher than the average $200 \mathrm{kHz}$ oscillations noted in this study. At a given flow rate and specific energy level the subsonic-arc-attachment thruster operated at temperatures much higher than those encountered with standard designs. The temperatures reported in Ref. 19 ranged from $600{ }^{\circ} \mathrm{C}$ to $900{ }^{\circ} \mathrm{C}$ for specific energy levels between 75 and $200 \mathrm{MJ} / \mathrm{kg}$, while the upper limit of $2000{ }^{\circ} \mathrm{C}$ was reached at the specific energy level of approximately $100 \mathrm{MJ} / \mathrm{kg}$. The radiation losses were nearly an order of magnitude greater in the subsonic design. The heat loss to the anode was greatly increased and caused a significant loss in performance. Anode material properties limit the amount of radiation shielding and regeneration that can be attained. Seating the arc foot closer to the throat may also decrease anode losses and boost efficiency.

\section{Concluding Remarks}

A subsonic-arc-attachment arcjet thruster was operated at $1-4 \mathrm{~kW}$ on hydrogen. The voltage stability of the thruster was strongly affected by current and propellant flow rates. Three operating regimes were identified. At low current and flow rates the voltage was stable. As either parameter was raised the arc entered a transition zone characterized by periods of $200 \mathrm{kHz}$ voltage oscillations caused by movement of the arc attachment point on the anode. Further increases in the current or propellant flow rate caused the voltage oscillations to become continuous. At a given specific energy level, specific impulse increased asymptotically with flow rate. The propellant injection scheme was also determined to affect performance. In particular, the creation of a vortex in the flow improved specific impulse and efficiency. Finally, variations in the facility background pressure caused changes in the V-I characteristic and voltage stability. Performance was enhanced by decreasing the facility pressure from $18 \mathrm{~Pa}$ to $0.047 \mathrm{~Pa}$.

The subsonic-arc-attachment thruster operated radically different than conventional designs. Performance of this device was found to be below that of existing designs; however, this design lacked any optimization. Before a valid judgement can be made between the superiority of one device over the other, several issues need to be addressed. First, a parametric investigation needs to be completed to evaluate the effects of electrode geometry on performance. The investigation should encompass variations in the throat diameter, arc chamber geometry, area ratio, and electrode spacing. The limit of vortex strength on performance enhancement needs to also be determined. The fact that this device operated at greatly elevated temperatures, while still producing reasonable performance levels, offers hope for increasing performance. Anode 
losses are often easier to recover than dissociation losses; although, the higher temperatures encountered with the subsonic-arc-attachment arcjet present material challenges.

\section{References}

1. John, R.R., "Thirty-Kilowatt Plasmajet Rocket Engine Development," Summary Report on the Second Year Development Program, Avco Corp, RAD-TR-64-6, (also NASA CR-54044), July 1964.

2. Todd, J.P. and Sheets, R.E., "Development of a Regeneratively Cooled 30-kW Arcjet Engine," AIAA Journal, Vol. 3, No. 1, pp. 122-126, 1965.

3. Sankovic, J.M., et al., "Hydrogen Arcjet Technology," IEPC 91-018, Proceedings of the 22nd International Electric Propulsion Conference, (also NASA TM 105340), October 1991.

4. Sanks, T.M., et al., "The Status and Future Plans for Electric Propulsion Development by the United States Air Force," IEPC 91-006, Proceedings of the 22nd International Electric Propulsion Conference, October 1991.

5. Polk, J.E. and Goodfellow, K.D., "Endurance Test of an Ammonia Arcjet at $10 \mathrm{kWe}$," IEPC 91-068, Proceedings of the 22nd International Electric Propulsion Conference, October 1991.

6. Haag, T.M. and Curran, F.M., "HighPower Hydrogen Arcjet Performance," AIAA 91-2226, (also NASA TM 105143), June 1991.

7. Hamley, J.A., et al., "10 kW Power Electronics for Hydrogen Arcjets," Proceedings of the 1992 JANNAF Propulsion Conference, (also NASA TM 105614), February 1992.

8. Curran, F.M., et al., "Performance Characterization of a Segmented Anode Arcjet Thruster," AIAA 90-2582, (also NASA TM 103227), July 1990.

9. "H2 Arcjet Performance Mapping Program," Rocket Research Co. Report
92-R-1615 (also NASA CR 191073), January 1992.

10. Haag, T.M., "Recent Testing of 30-kW Hydrogen Arcjet Thrusters," AIAA 931902, June 1993.

11. Berns, D.H. and Sankovic, J.M., "Investigation of a Subsonic-ArcAttachment Thruster Using SegmentedAnodes," AIAA 93-1899, June 1993.

12. Curran, F.M. and Haag, T.W., "Arcjet Component Conditions Through a Multistart Test," AIAA 87-1060, (also NASA TM 89857), May 1987.

13. Gruber, R.P., Gott, R.W., and Haag, T.W., "5-kW Arcjet Power Electronics," AIAA 89-2725, (also NASA TM 102108), July 1989.

14. Haag, T.W. and Curran, F.M., "Arcjet Starting Reliability: A Multistart Test," AIAA 87-1061, (also NASA TM 89867), May 1987.

15. Morren, W.E. and Lichon, P.J., "Low Power Arcjet Test Facility Impacts," AIAA 92-3532, (also NASA TM 105876), July 1992.

16. Curran, F.M., et al.,"Medium Power Hydrogen Arcjet Performance," AIAA 912227, (also NASA TM 104533), June 1991.

17. Todd, J.P., et al., "Development of a Thermal Arc Engine," ASD-TDR-62749, July 1962.

18. Hamley, J.A., "Arcjet Load Characteristics," AIAA 90-2579, (also NASA TM 103190), July 1990.

19. Sankovic, J.M. and Curran, F.M., "Arcjet Thermal Characteristics," AIAA 91-2456, (also NASA TM 105156), June 1991.

20. Curran, F.M., et al.,"Arcjet Nozzle Area Ratio Effects," Proceedings of the 1990 JANNAF Propulsion Conference, (also NASA TM 104477), October 1990. 
Table I. - Subsonic-Arc-Attachment Arcjet Scaling

\begin{tabular}{|c|c|c|}
\hline & GSC & NASA LeRC \\
\hline Power (kW) & 30 & 3 \\
Propellant Flow Rate (mg/s) & 330 & 33 \\
Specific Energy (MJ/kg) & 91 & 91 \\
Minimum Throat Diameter (cm) & 0.475 & 0.152 \\
Area Ratio & 60 & 39 \\
Anode Diverging Side Half Angle (deg) & 15 & 15 \\
Cathode Half Angle (deg) & 30 & 30 \\
\hline
\end{tabular}


Table II. - Performance data for thruster with tangential gas injection and facility background pressures greater than $18 \mathrm{~Pa}$

\begin{tabular}{|c|c|c|c|c|c|c|c|c|}
\hline Voltage & Current & Power & $\begin{array}{l}\text { Propellant } \\
\text { Flow Rate }\end{array}$ & $\begin{array}{c}\text { Specific } \\
\text { Energy }\end{array}$ & $\begin{array}{c}\text { Propellant } \\
\text { Feed Pressure }\end{array}$ & Thrust & $\begin{array}{l}\text { Specific } \\
\text { Impulse }\end{array}$ & Efficiency \\
\hline $\mathrm{V}$ & $\mathrm{A}$ & W & $\mathrm{mg} / \mathrm{s}$ & $\mathrm{MJ} / \mathrm{kg}$ & $\mathrm{kPa}$ & $\mathrm{mN}$ & $s$ & \\
\hline 85.0 & 4.0 & 343 & 10.0 & 34.4 & 156.8 & 48.9 & 499 & 0.349 \\
\hline 121.5 & 6.0 & 725 & 10.0 & 72.6 & 172.3 & 59.0 & 603 & 0.241 \\
\hline 121.5 & 6.0 & 724 & 10.0 & 72.5 & 172.1 & 58.9 & 601 & 0.239 \\
\hline 76.2 & 7.1 & 539 & 10.0 & 54.0 & 160.3 & 51.8 & 529 & 0.249 \\
\hline 86.7 & 8.0 & 696 & 10.0 & 69.7 & 172.2 & 55.1 & 562 & 0.218 \\
\hline 76.0 & 8.0 & 609 & 10.0 & 61.0 & 172.3 & 53.4 & 544 & 0.234 \\
\hline 81.8 & 10.0 & 818 & 10.0 & 81.9 & 177.0 & 57.2 & 584 & 0.200 \\
\hline 73.4 & 10.0 & 734 & 10.0 & 73.5 & 176.8 & 55.9 & 571 & 0.213 \\
\hline 64.4 & 10.0 & 644 & 10.0 & 64.5 & 167.2 & 53.3 & 544 & 0.221 \\
\hline 55.9 & 12.0 & 672 & 10.0 & 67.5 & 165.7 & 53.3 & 546 & 0.212 \\
\hline 57.7 & 12.0 & 694 & 10.0 & 69.6 & 166.6 & 52.4 & 536 & 0.199 \\
\hline 78.2 & 12.0 & 938 & 10.0 & 93.9 & 181.6 & 58.4 & 596 & 0.182 \\
\hline 73.6 & 12.0 & 882 & 10.0 & 88.3 & 182.0 & 58.4 & 596 & 0.194 \\
\hline 54.3 & 14.0 & 760 & 10.0 & 76.1 & 177.8 & 55.5 & 566 & 0.203 \\
\hline 66.3 & 14.0 & 927 & 10.0 & 92.9 & 182.5 & 58.1 & 593 & 0.182 \\
\hline 66.4 & 16.0 & 1067 & 10.0 & 106.8 & 182.5 & 58.9 & 601 & 0.163 \\
\hline 60.6 & 16.0 & 974 & 10.0 & 97.5 & 184.9 & 59.4 & 606 & 0.181 \\
\hline 59.7 & 18.0 & 1079 & 10.0 & 108.0 & 189.0 & 61.2 & 625 & 0.174 \\
\hline 61.8 & 18.0 & 1117 & 10.0 & 111.9 & 189.3 & 62.1 & 634 & 0.173 \\
\hline 142.6 & 10.2 & 1451 & 20.0 & 72.5 & 316.8 & 138.5 & 705 & 0.330 \\
\hline 142.0 & 10.2 & 1446 & 20.0 & 72.3 & 317.3 & 138.7 & 707 & 0.333 \\
\hline 115.1 & 14.0 & 1607 & 20.0 & 79.5 & 305.6 & 133.4 & 681 & 0.281 \\
\hline 117.1 & 14.0 & 1635 & 20.0 & 81.0 & 323.8 & 137.0 & 699 & 0.291 \\
\hline 114.7 & 15.0 & 1719 & 20.0 & 85.2 & 335.5 & 140.4 & 717 & 0.290 \\
\hline 115.0 & 15.0 & 1723 & 20.0 & 85.2 & 336.1 & 140.7 & 718 & 0.291 \\
\hline 114.4 & 16.0 & 1830 & 20.0 & 90.6 & 340.4 & 143.9 & 735 & 0.287 \\
\hline 114.4 & 16.0 & 1831 & 20.0 & 90.6 & 340.0 & 144.0 & 735 & 0.287 \\
\hline 112.1 & 17.0 & 1904 & 20.0 & 94.2 & 343.1 & 145.8 & 744 & 0.283 \\
\hline 112.2 & 17.0 & 1905 & 20.0 & 94.4 & 343.1 & 145.8 & 745 & 0.283 \\
\hline 110.9 & 19.0 & 2109 & 20.0 & 104.4 & 351.4 & 150.0 & 766 & 0.270 \\
\hline 110.6 & 19.0 & 2102 & 20.0 & 103.8 & 350.2 & 149.8 & 765 & 0.271 \\
\hline 108.1 & 20.0 & 2162 & 20.0 & 107.1 & 351.3 & 150.6 & 768 & 0.265 \\
\hline 104.6 & 20.0 & 2092 & 20.0 & 103.8 & 351.7 & 151.2 & 772 & 0.276 \\
\hline 176.5 & 4.5 & 796 & 30.0 & 26.5 & 350.6 & 158.9 & 530 & 0.510 \\
\hline 165.0 & 5.1 & 840 & 30.0 & 28.0 & 351.6 & 160.6 & 536 & 0.493 \\
\hline 153.9 & 5.9 & 913 & 30.0 & 30.4 & 361.5 & 165.9 & 554 & 0.484 \\
\hline 139.9 & 8.0 & 1117 & 30.0 & 37.2 & 379.7 & 177.1 & 591 & 0.451 \\
\hline 131.7 & 10.0 & 1322 & 30.0 & 44.1 & 406.0 & 188.8 & 630 & 0.434 \\
\hline 113.2 & 14.0 & 1582 & 30.0 & 52.7 & 452.5 & 205.1 & 685 & 0.428 \\
\hline 116.8 & 14.0 & 1632 & 30.0 & 54.5 & 442.4 & 205.1 & 686 & 0.415 \\
\hline 115.4 & 15.0 & 1728 & 30.0 & 57.7 & 445.7 & 208.1 & 695 & 0.403 \\
\hline 115.5 & 15.0 & 1729 & 30.0 & 57.6 & 446.2 & 208.4 & 696 & 0.404 \\
\hline 113.3 & 16.0 & 1813 & 30.0 & 60.4 & 450.3 & 211.2 & 705 & 0.396 \\
\hline 113.6 & 16.0 & 1818 & 30.0 & 60.6 & 451.9 & 211.7 & 707 & 0.397 \\
\hline 109.9 & 18.0 & 1973 & 30.0 & 65.8 & 460.1 & 216.9 & 724 & 0.384 \\
\hline 110.2 & 18.0 & 1980 & 30.0 & 66.1 & 461.2 & 217.2 & 725 & 0.383 \\
\hline 106.3 & 20.0 & 2127 & 30.0 & 70.9 & 466.5 & 221.5 & 740 & 0.371 \\
\hline 106.5 & 20.0 & 2131 & 30.0 & 71.1 & 469.5 & 222.1 & 741 & 0.372 \\
\hline 103.7 & 22.0 & 2284 & 30.0 & 76.1 & 473.9 & 226.2 & 755 & 0.360 \\
\hline 104.2 & 22.0 & 2296 & 30.0 & 76.6 & 477.7 & 227.2 & 759 & 0.362 \\
\hline 102.3 & 24.0 & 2456 & 30.0 & 81.9 & 484.8 & 231.8 & 774 & 0.352 \\
\hline 102.3 & 24.0 & 2453 & 30.0 & 81.8 & 485.2 & 231.9 & 775 & 0.353 \\
\hline 100.7 & 26.0 & 2616 & 30.0 & 87.2 & 491.6 & 236.3 & 789 & 0.343 \\
\hline 100.8 & 26.0 & 2619 & 30.0 & 87.3 & 491.8 & 236.4 & 789 & 0.343 \\
\hline 99.5 & 28.0 & 2782 & 30.0 & 92.8 & 497.4 & 240.5 & 803 & 0.335 \\
\hline 99.6 & 28.0 & 2784 & 30.0 & 92.9 & 498.0 & 240.8 & 804 & 0.335 \\
\hline 98.1 & 30.0 & 2941 & 30.0 & 98.1 & 501.5 & 244.5 & 816 & 0.327 \\
\hline 98.4 & 30.0 & 2953 & 30.0 & 98.5 & 503.5 & 245.1 & 819 & 0.327 \\
\hline 127.0 & 20.0 & 2543 & 42.0 & 64.0 & 557.2 & 295.8 & 719 & 0.392 \\
\hline 124.0 & 24.0 & 2978 & 42.0 & 74.0 & 583.2 & 314.6 & 764 & 0.378 \\
\hline 121.7 & 28.0 & 3407 & 42.0 & 85.0 & 606.7 & 331.9 & 806 & 0.368 \\
\hline 120.6 & 31.3 & 3776 & 42.0 & 94.0 & 623.7 & 345.4 & 839 & 0.359 \\
\hline
\end{tabular}


Table III. - Performance data for thruster with radial gas injection

\begin{tabular}{|c|c|c|c|c|c|c|c|c|}
\hline Voltage & Current & Power & $\begin{array}{l}\text { Propellant } \\
\text { Flow Rate }\end{array}$ & $\begin{array}{c}\text { Specific } \\
\text { Energy }\end{array}$ & $\begin{array}{c}\text { Propellant } \\
\text { Feed Pressure }\end{array}$ & Thrust & $\begin{array}{l}\text { Specific } \\
\text { Impulse }\end{array}$ & Efficiency \\
\hline V & A & $W$ & $\mathrm{mg} / \mathrm{s}$ & $\mathrm{MJ} / \mathrm{kg}$ & $\mathrm{kPa}$ & $\mathrm{mN}$ & 5 & \\
\hline 64.7 & 16.0 & 1029 & 15.0 & 69.0 & 102.7 & 86.5 & 587 & 0.242 \\
\hline 86.7 & 16.0 & 1379 & 20.0 & 69.0 & 122.2 & 132.3 & 674 & 0.317 \\
\hline 70.7 & 16.0 & 1125 & 20.0 & 56.0 & 121.2 & 116.2 & 592 & 0.300 \\
\hline 89.7 & 16.0 & 1428 & 20.0 & 70.0 & 129.3 & 130.3 & 655 & 0.293 \\
\hline 87.2 & 18.0 & 1567 & 20.0 & 78.0 & 128.6 & 133.6 & 681 & 0.285 \\
\hline 80.7 & 18.0 & 1451 & 20.0 & 72.0 & 127.8 & 129.4 & 658 & 0.288 \\
\hline 83.4 & 20.0 & 1665 & 20.0 & 83.0 & 129.7 & 136.8 & 697 & 0.281 \\
\hline 83.2 & 21.0 & 1787 & 20.0 & 89.0 & 130.5 & 138.9 & 708 & 0.270 \\
\hline 69.6 & 22.0 & 1530 & 20.0 & 77.0 & 129.4 & 134.1 & 684 & 0.294 \\
\hline 83.0 & 22.0 & 1826 & 20.0 & 91.0 & 131.6 & 141.0 & 718 & 0.272 \\
\hline 104.3 & 14.0 & 1460 & 30.0 & 49.0 & 142.7 & 173.4 & 578 & 0.330 \\
\hline 104.2 & 14.0 & 1460 & 30.0 & 49.0 & 144.9 & 174.7 & 582 & 0.336 \\
\hline 100.2 & 16.0 & 1594 & 30.0 & 53.0 & 158.8 & 191.0 & 637 & 0.367 \\
\hline
\end{tabular}

Table IV. - Performance data for thruster with tangential gas injection and facility background pressure of $0.047 \mathrm{~Pa}$

\begin{tabular}{|c|c|c|c|c|c|c|c|c|}
\hline Voltage & Current & Power & $\begin{array}{l}\text { Propellant } \\
\text { Flow Rate }\end{array}$ & $\begin{array}{l}\text { Specific } \\
\text { Energy }\end{array}$ & $\begin{array}{c}\text { Propellant } \\
\text { Feed Pressure }\end{array}$ & Thrust & $\begin{array}{l}\text { Specific } \\
\text { Impulse }\end{array}$ & Efficiency \\
\hline $\mathrm{V}$ & A & W & $\mathrm{mg} / \mathrm{s}$ & $\mathrm{MJ} / \mathrm{kg}$ & $\mathrm{kPa}$ & $\mathrm{mN}$ & $s$ & \\
\hline 145.9 & 4.2 & 609 & 10.0 & 60.9 & 165.4 & 59.1 & 603 & 0.287 \\
\hline 126.0 & 5.8 & 726 & 10.0 & 72.7 & 171.6 & 61.7 & 630 & 0.263 \\
\hline 121.0 & 7.1 & 862 & 10.0 & 86.2 & 173.6 & 62.3 & 636 & 0.226 \\
\hline 115.0 & 8.0 & 924 & 10.0 & 92.6 & 181.6 & 67.5 & 690 & 0.247 \\
\hline 103.8 & 10.0 & 1041 & 10.0 & 104.3 & 182.0 & 62.2 & 635 & 0.186 \\
\hline 105.9 & 10.2 & 1083 & 10.0 & 108.3 & 169.1 & 63.3 & 645 & 0.185 \\
\hline 97.4 & 12.1 & 1174 & 10.0 & 117.0 & 188.2 & 68.2 & 693 & 0.198 \\
\hline 92.3 & 14.0 & 1294 & 10.0 & 128.9 & 192.8 & 70.2 & 713 & 0.190 \\
\hline 89.3 & 16.0 & 1429 & 10.0 & 142.2 & 194.6 & 71.6 & 727 & 0.179 \\
\hline 61.3 & 16.0 & 981 & 10.0 & 97.8 & 194.0 & 66.3 & 674 & 0.224 \\
\hline 86.6 & 18.0 & 1562 & 10.0 & 155.5 & 197.9 & 73.6 & 747 & 0.173 \\
\hline 55.5 & 24.1 & 1335 & 10.0 & 132.8 & 198.6 & 74.7 & 758 & 0.208 \\
\hline 28.3 & 28.0 & 791 & 10.0 & 78.8 & 199.8 & 73.6 & 747 & 0.341 \\
\hline 56.8 & 28.0 & 1590 & 10.0 & 158.4 & 198.2 & 73.2 & 743 & 0.168 \\
\hline 41.8 & 27.6 & 1153 & 10.0 & 114.8 & 196.2 & 67.4 & 684 & 0.196 \\
\hline
\end{tabular}




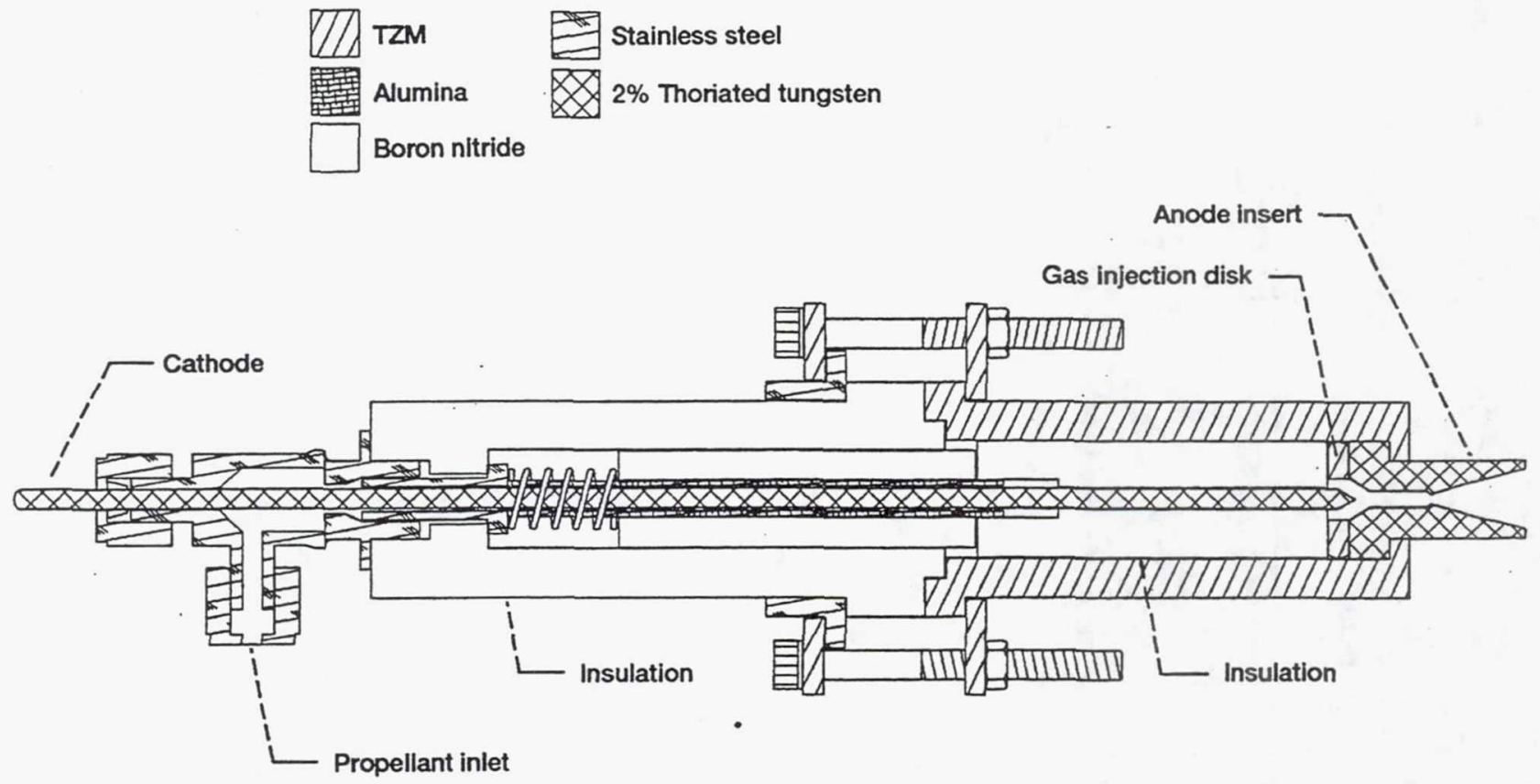

Figure 1.-Arcjet thruster cross sectional schematic.

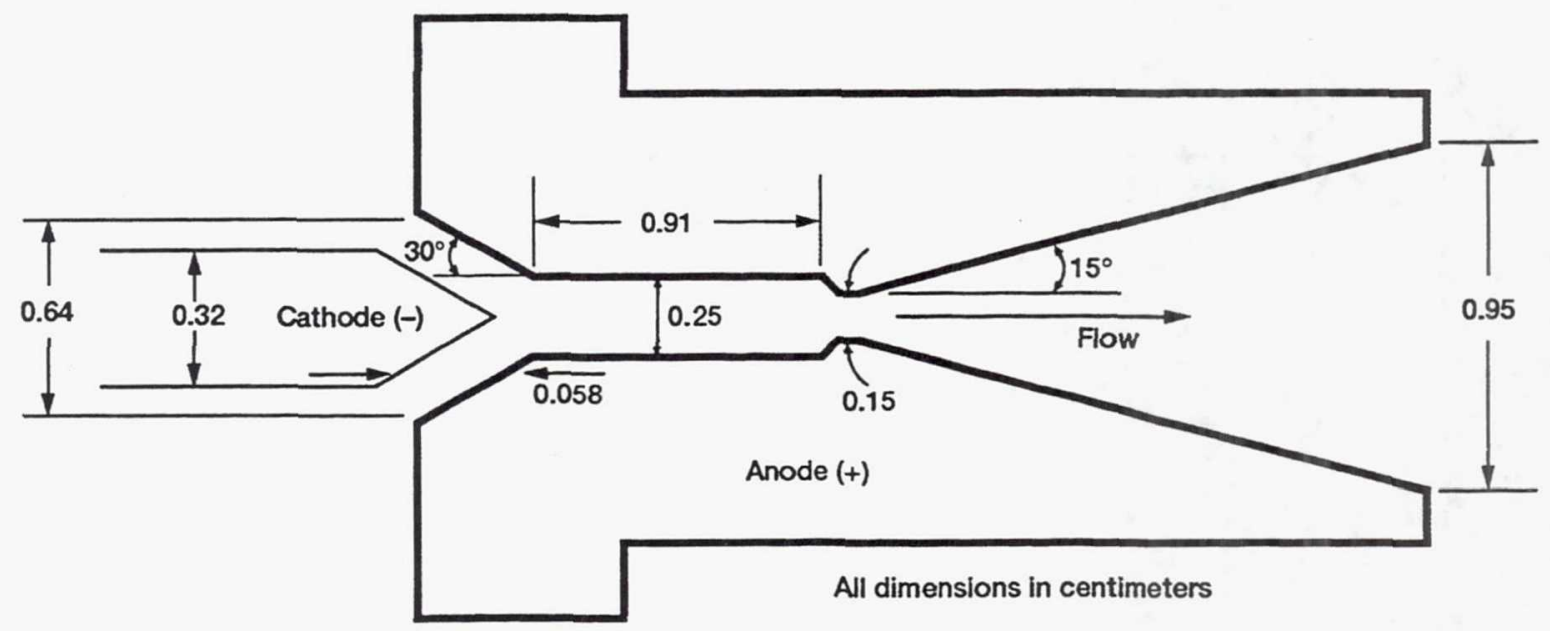

Figure 2.-Electrode geometry. 


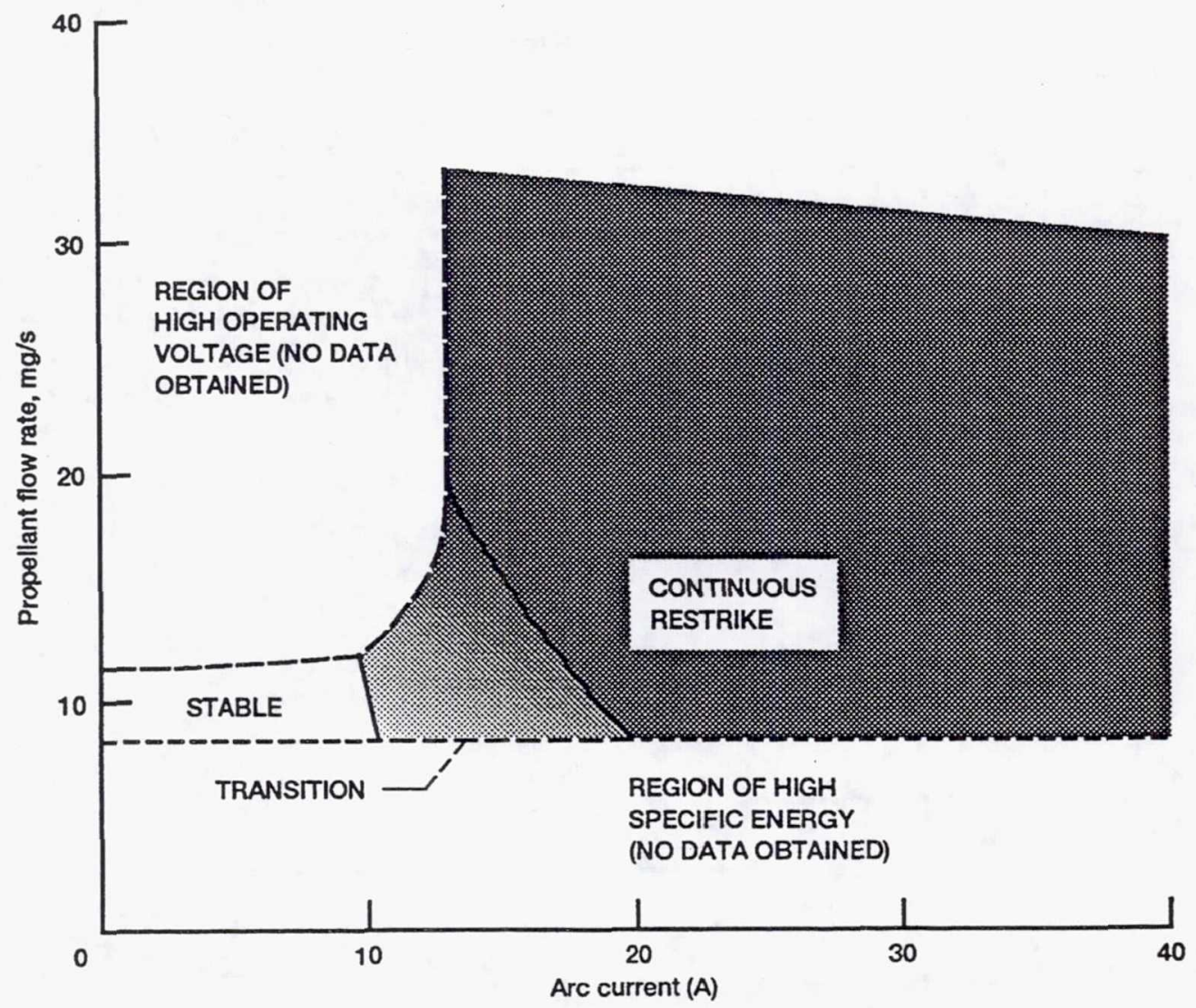

Figure 3.-Thruster stability map. 


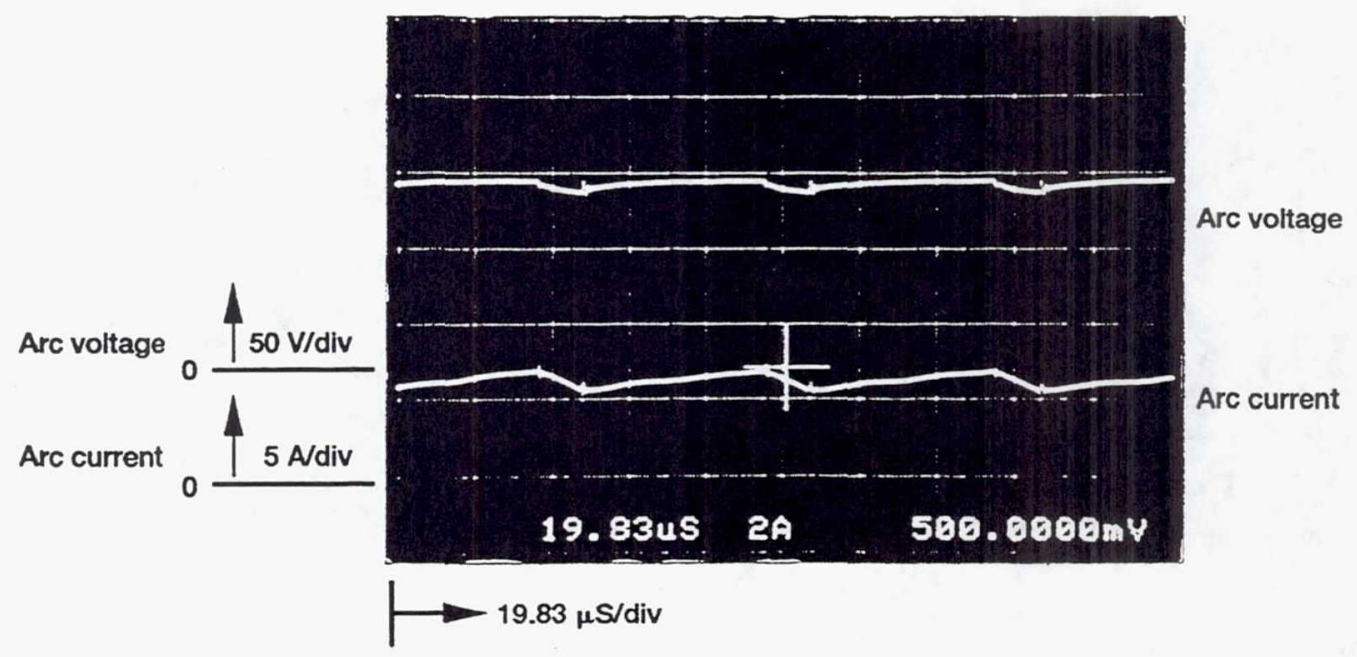

(a) $10 \mathrm{mg} / \mathrm{s} ; 6 \mathrm{~A}$.

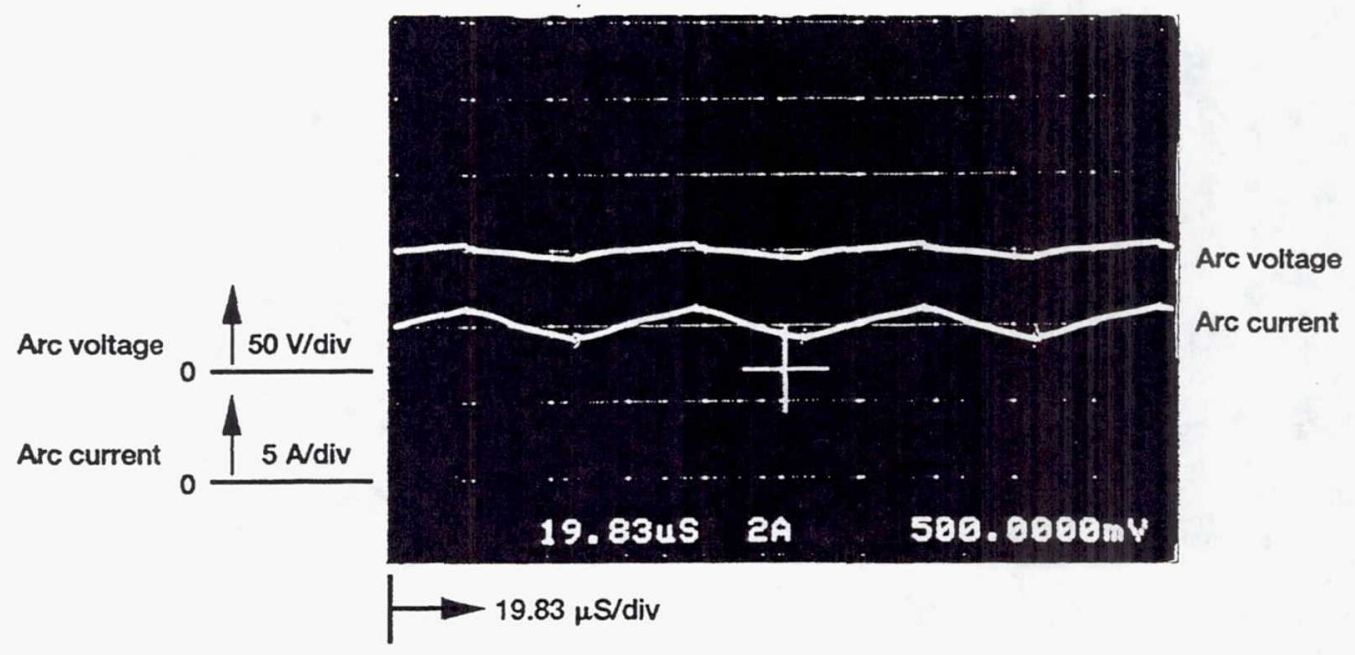

(b) $10 \mathrm{mg} / \mathrm{s} ; 10 \mathrm{~A}$.

Figure 4.-Oscilloscope traces showing onset of arc voltage instabilities with increasing arc current at a constant propellant flow rate. 


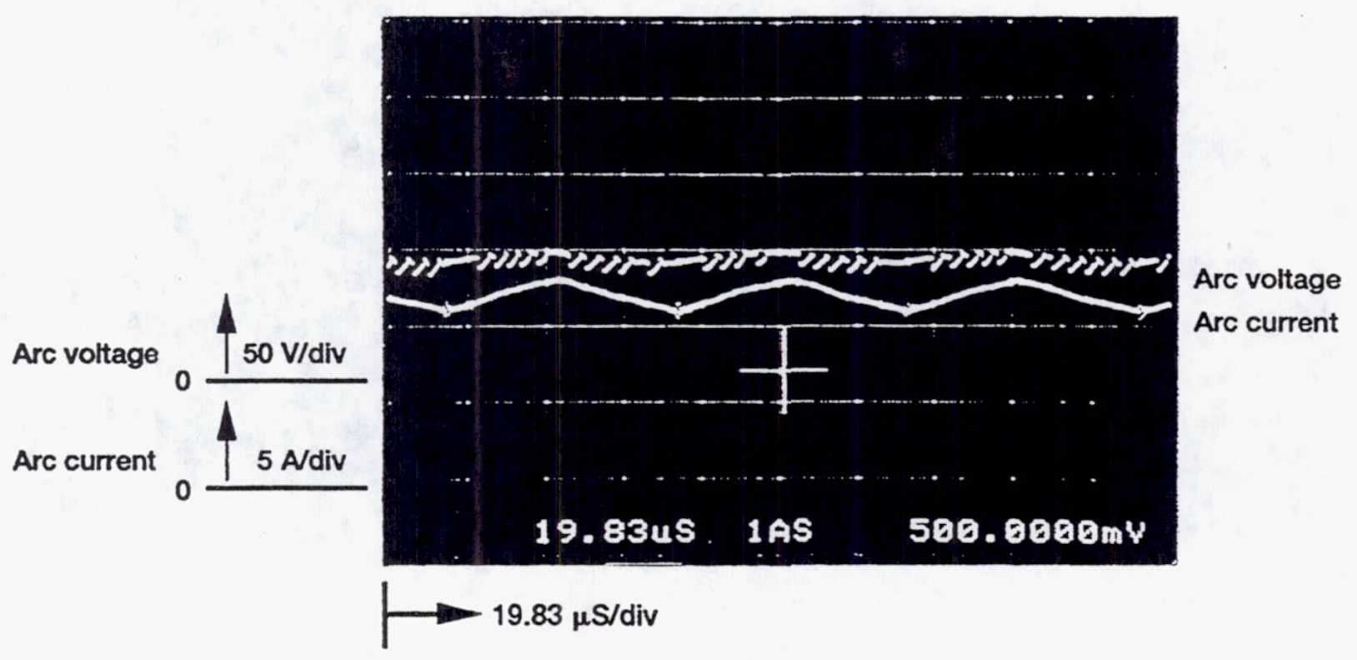

(c) $10 \mathrm{mg} / \mathrm{s} ; 12 \mathrm{~A}$.

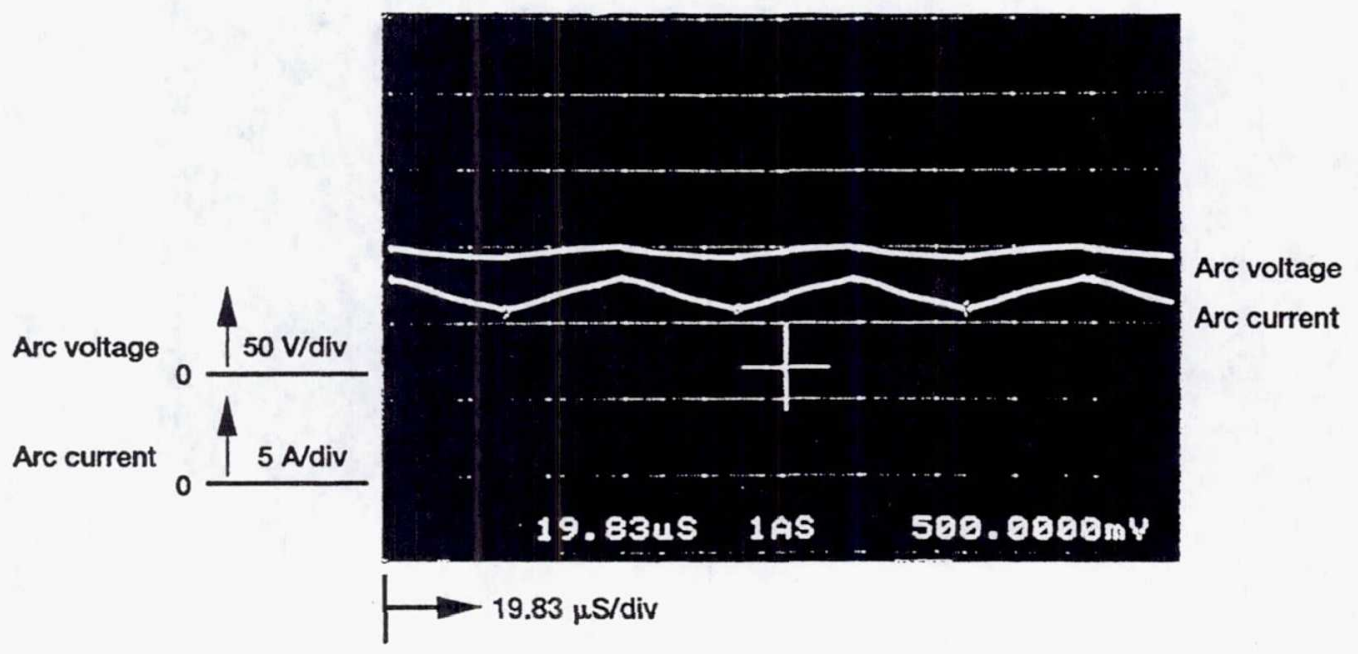

(d) $10 \mathrm{mg} / \mathrm{s} ; 12 \mathrm{~A}$.

Figure 4.-Continued. 


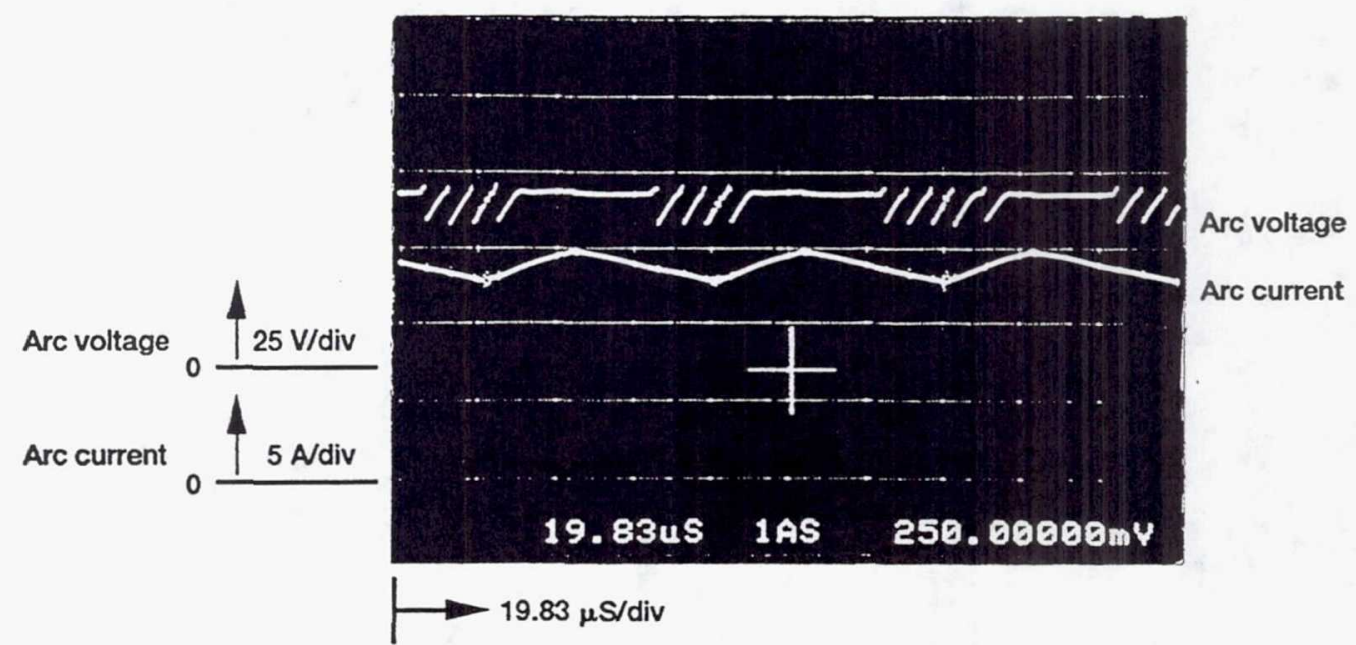

(e) $10 \mathrm{mg} / \mathrm{s} ; 14 \mathrm{~A}$.

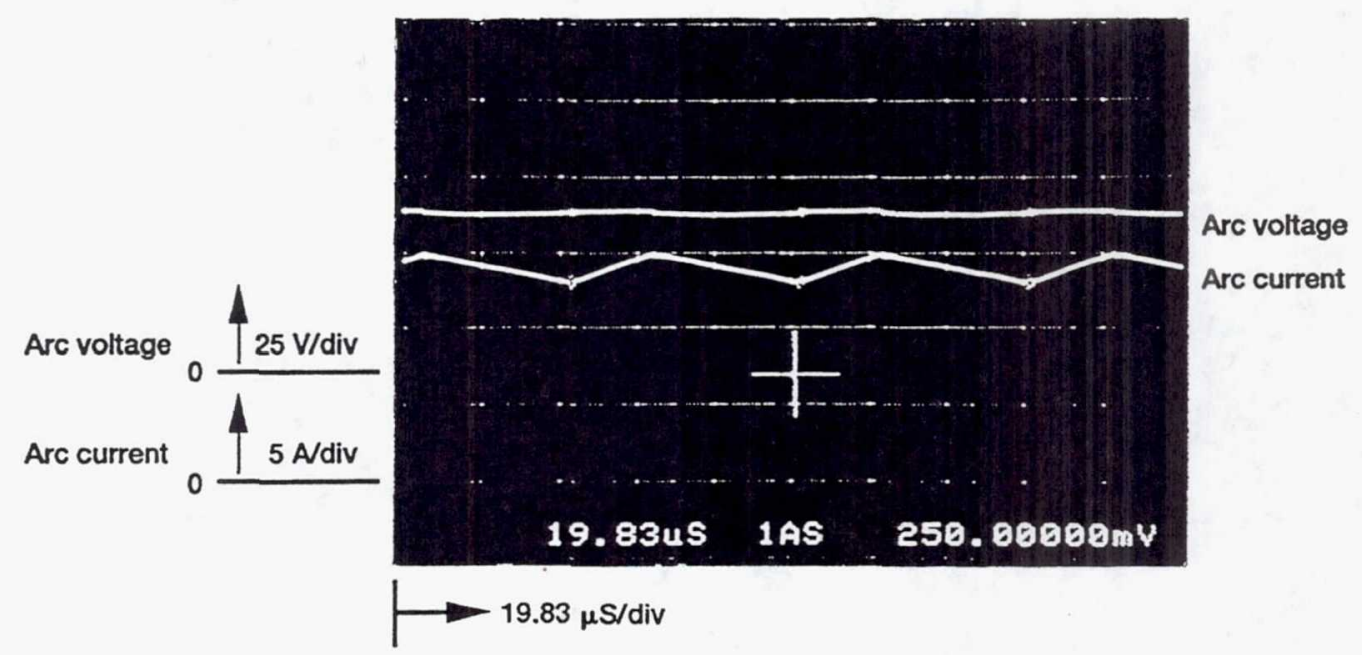

(f) $10 \mathrm{mg} / \mathrm{s} ; 14 \mathrm{~A}$.

Figure 4.-Continued. 


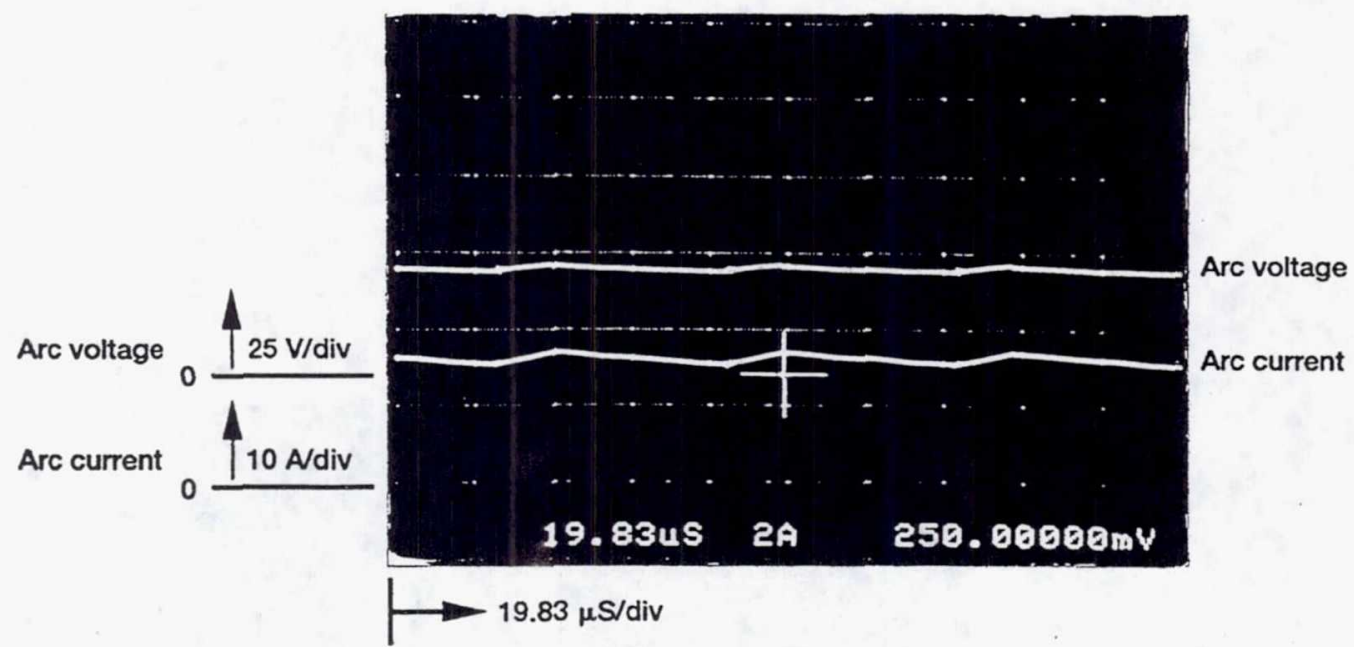

(g) $10 \mathrm{mg} / \mathrm{s} ; 16 \mathrm{~A}$.

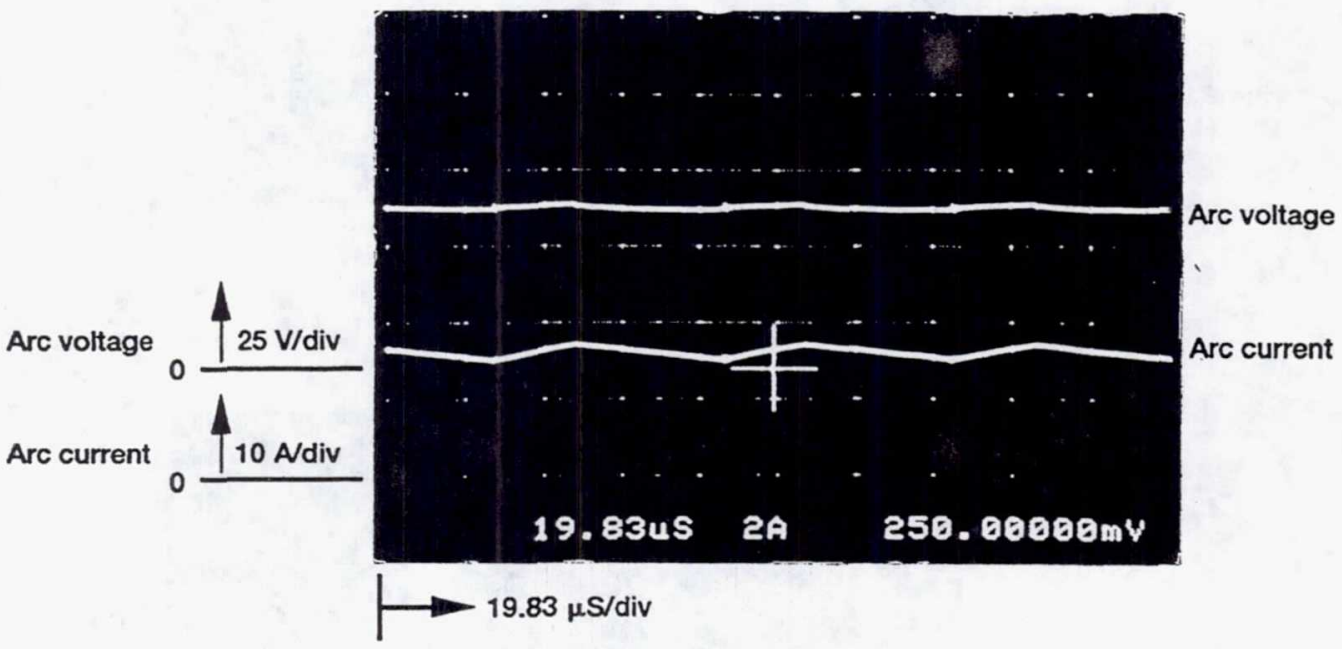

(h) $10 \mathrm{mg} / \mathrm{s} ; 16 \mathrm{~A}$.

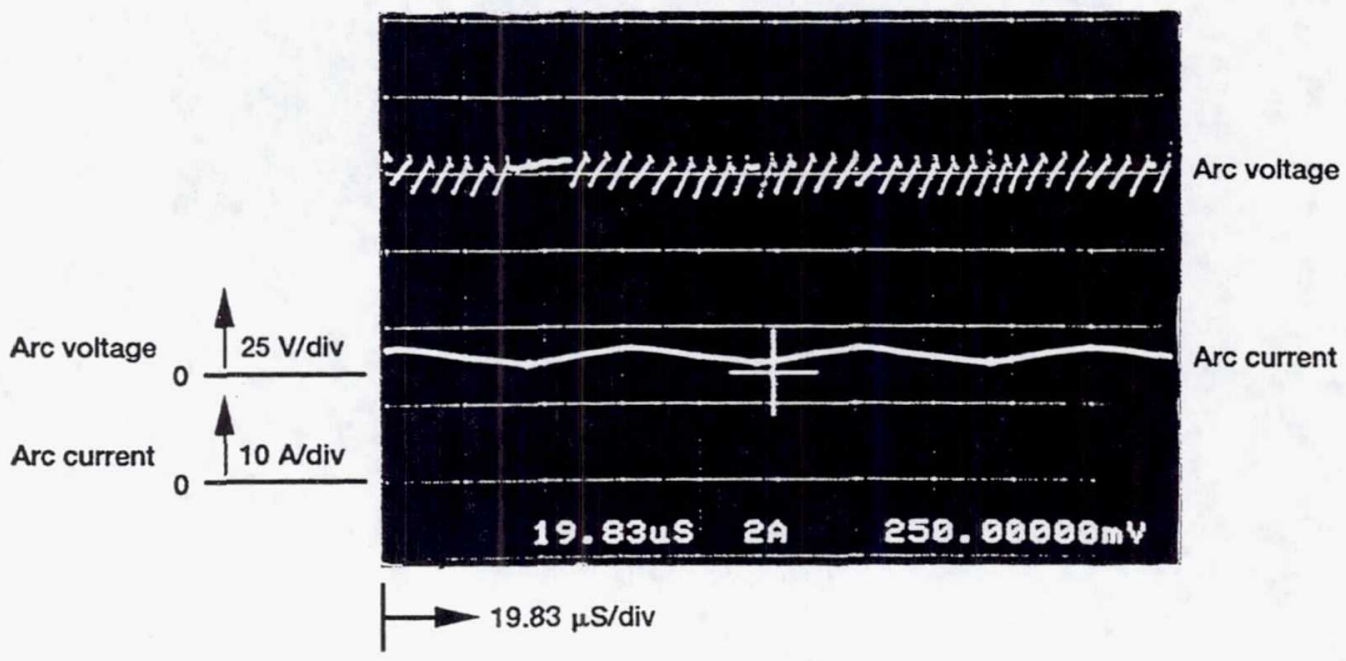

(i) $10 \mathrm{mg} / \mathrm{s} ; 16 \mathrm{~A}$.

Figure 4.-Continued. 


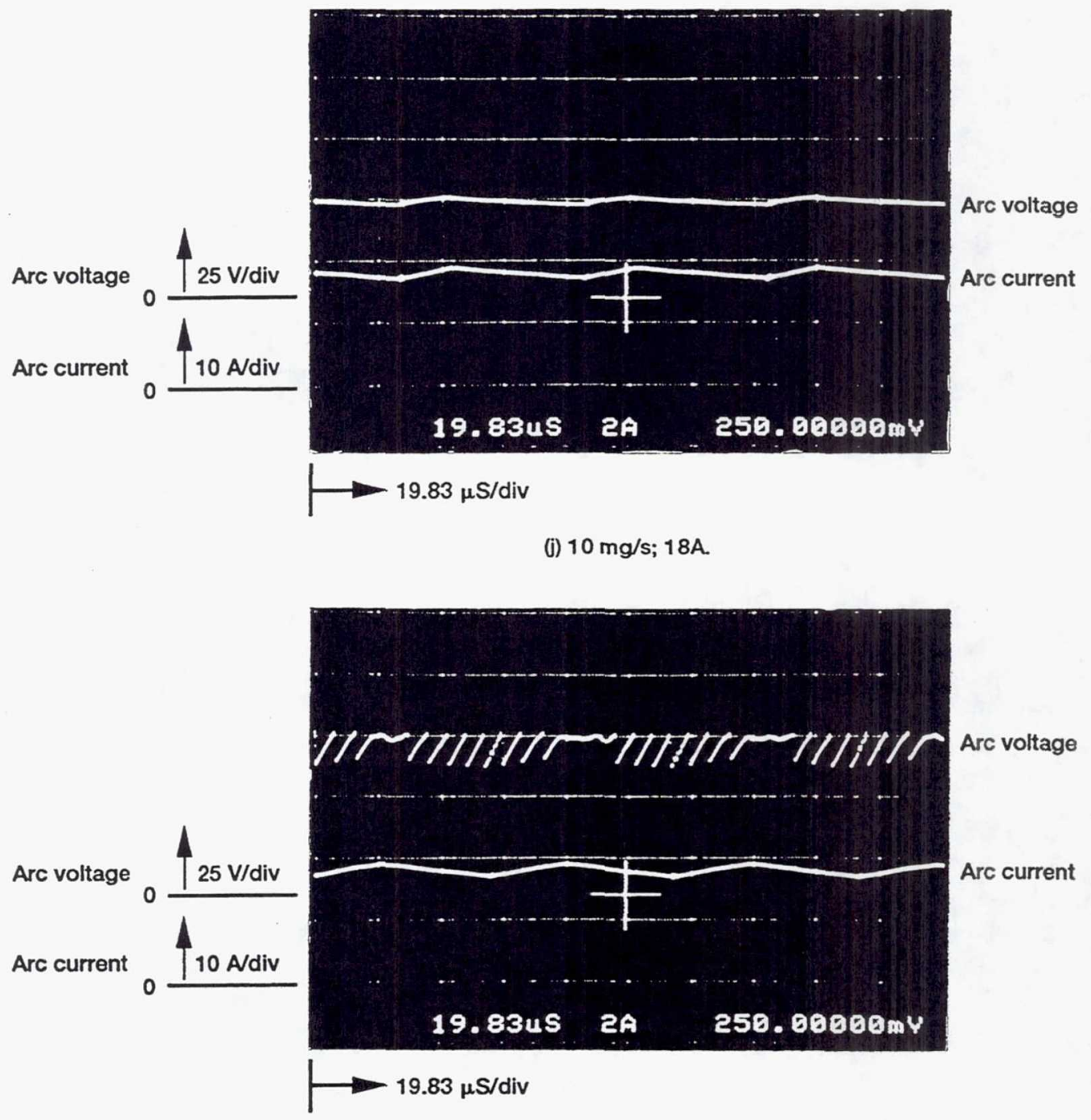

(k) $10 \mathrm{mg} / \mathrm{s} ; 18 \mathrm{~A}$

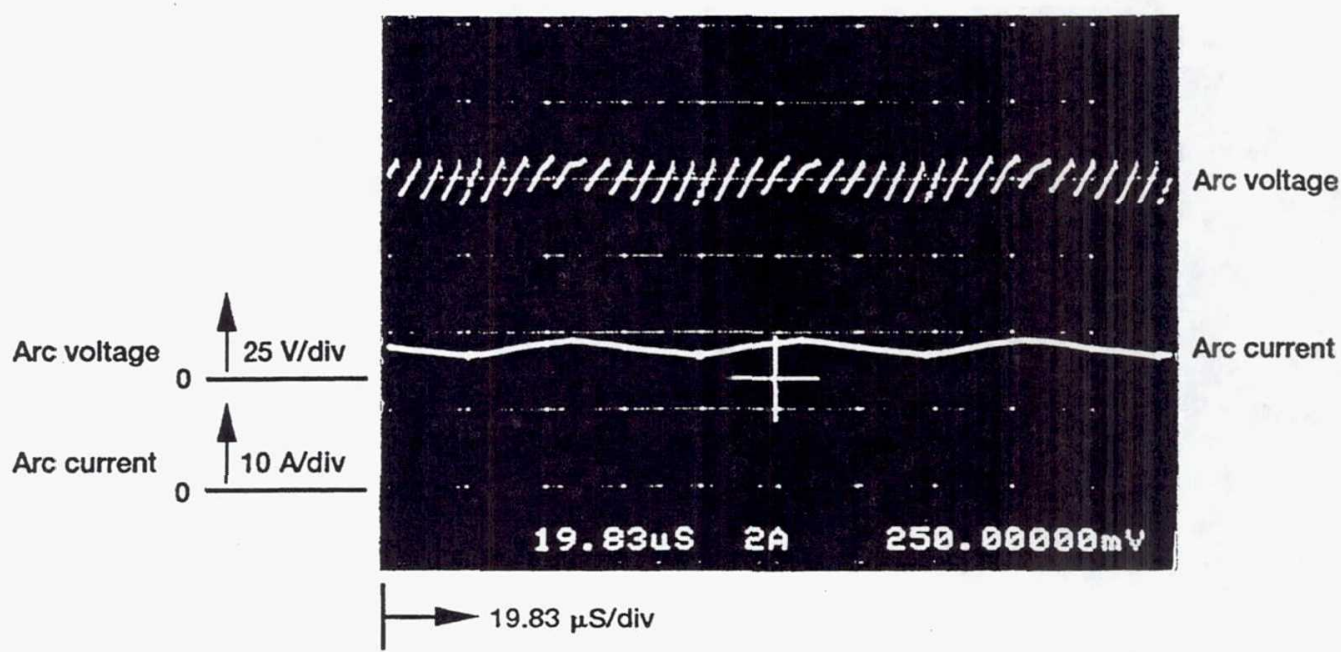

(I) $10 \mathrm{mg} / \mathrm{s} ; 18 \mathrm{~A}$.

Figure 4.-Concluded. 


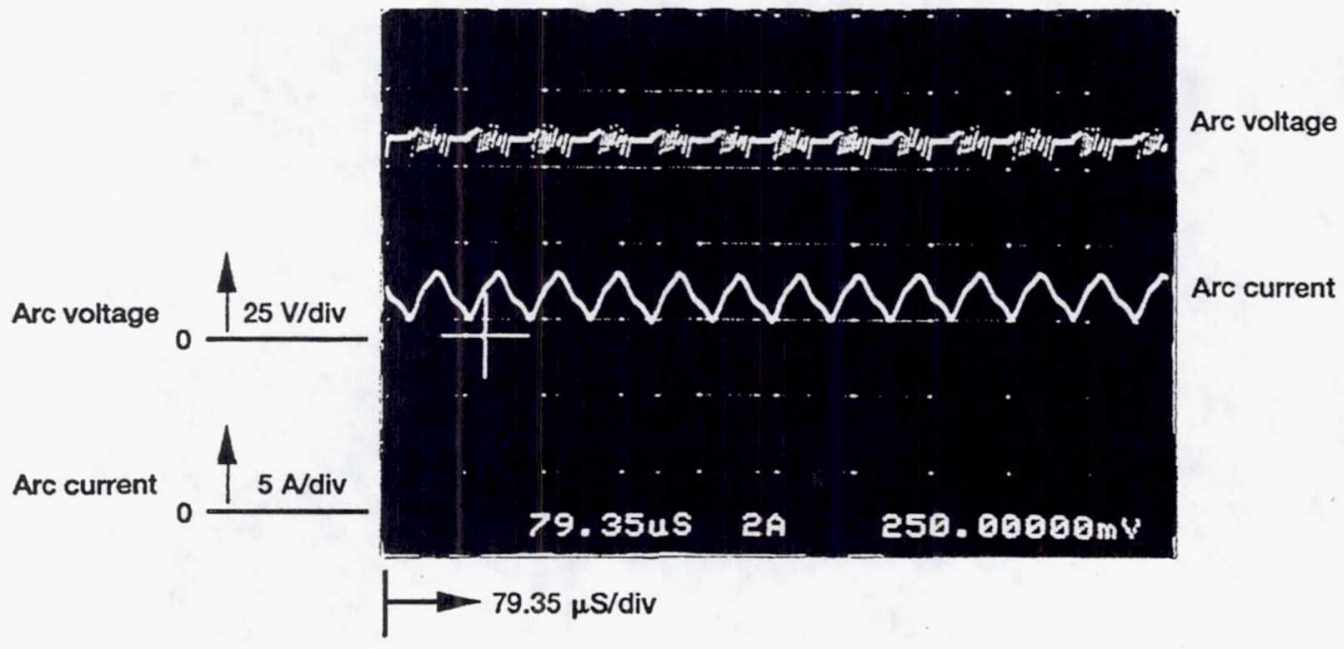

(a) $10 \mathrm{mg} / \mathrm{s} ; 14 \mathrm{~A}$.

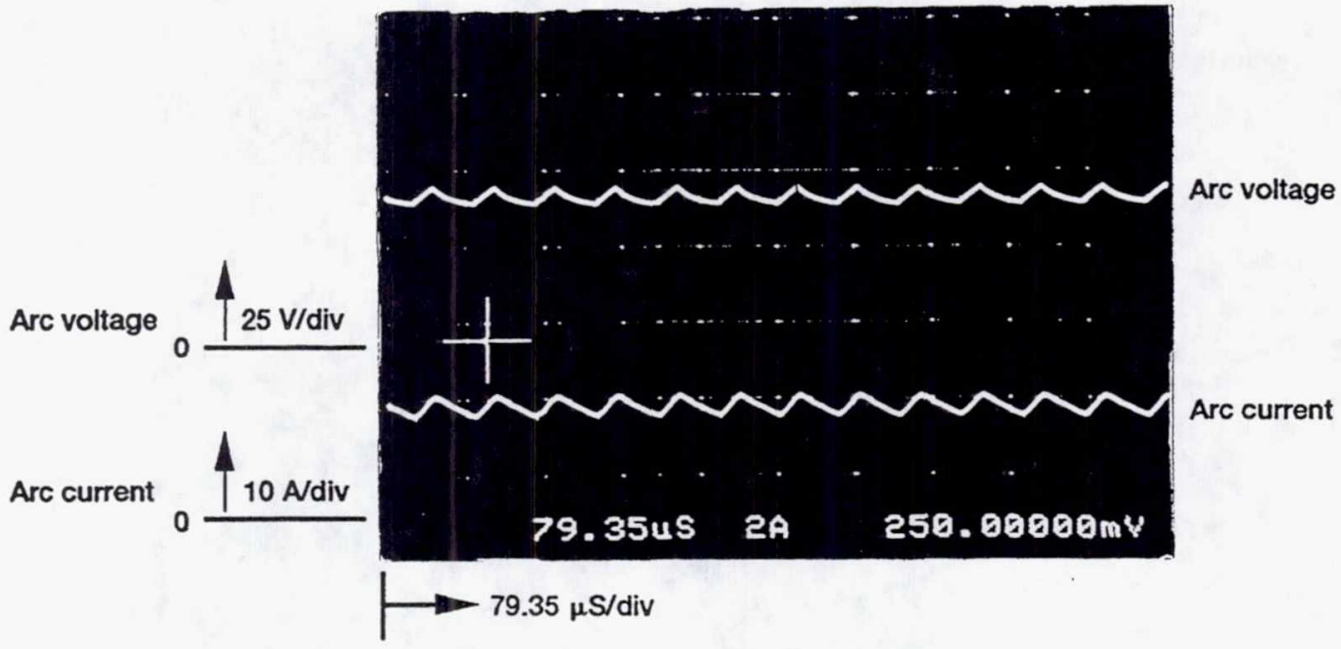

(b) $10 \mathrm{mg} / \mathrm{s} ; 14 \mathrm{~A}$.

Figure 5.-Oscilloscope traces showing onset of arc voltage instabilities with increasing propellant flow rate at constant arc current. 


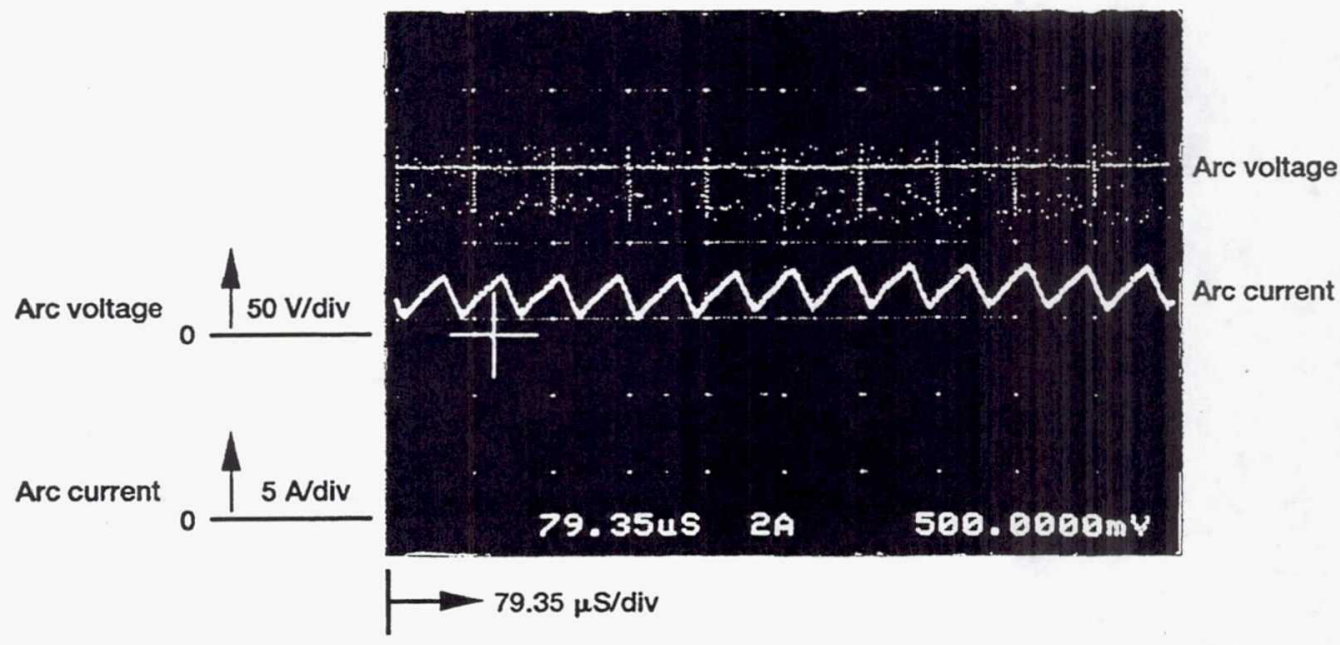

(c) $20 \mathrm{mg} / \mathrm{s} ; 14 \mathrm{~A}$.

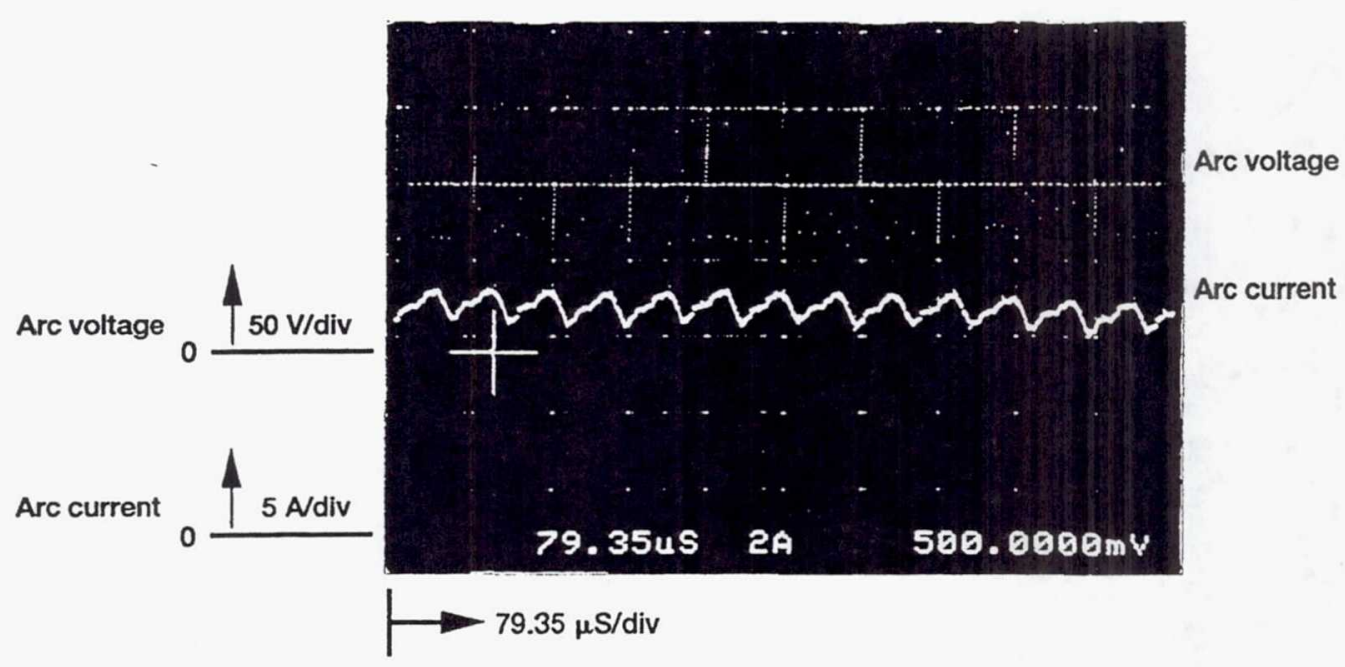

(d) $30 \mathrm{mg} / \mathrm{s} ; 14 \mathrm{~A}$.

Figure 5.-Concluded. 


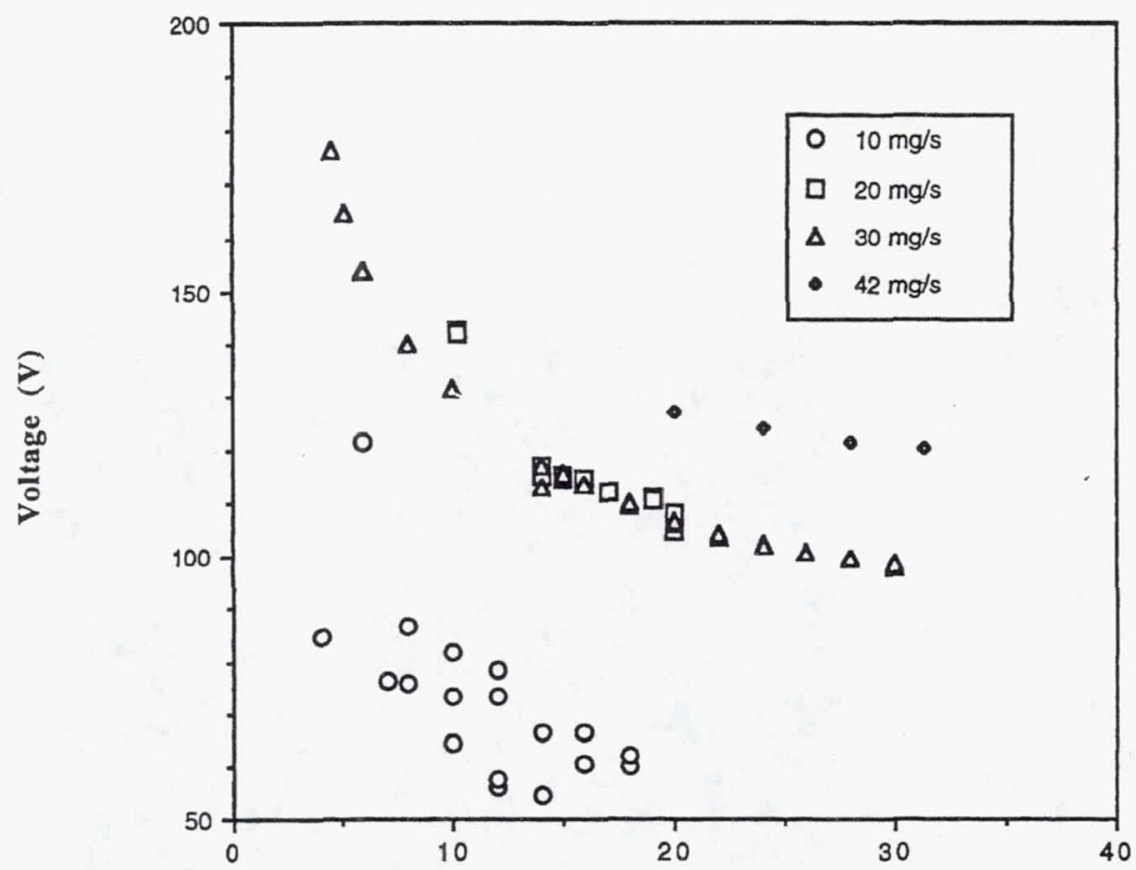

Current (A)

Figure 6.-Arcjet voltage-current characteristics.

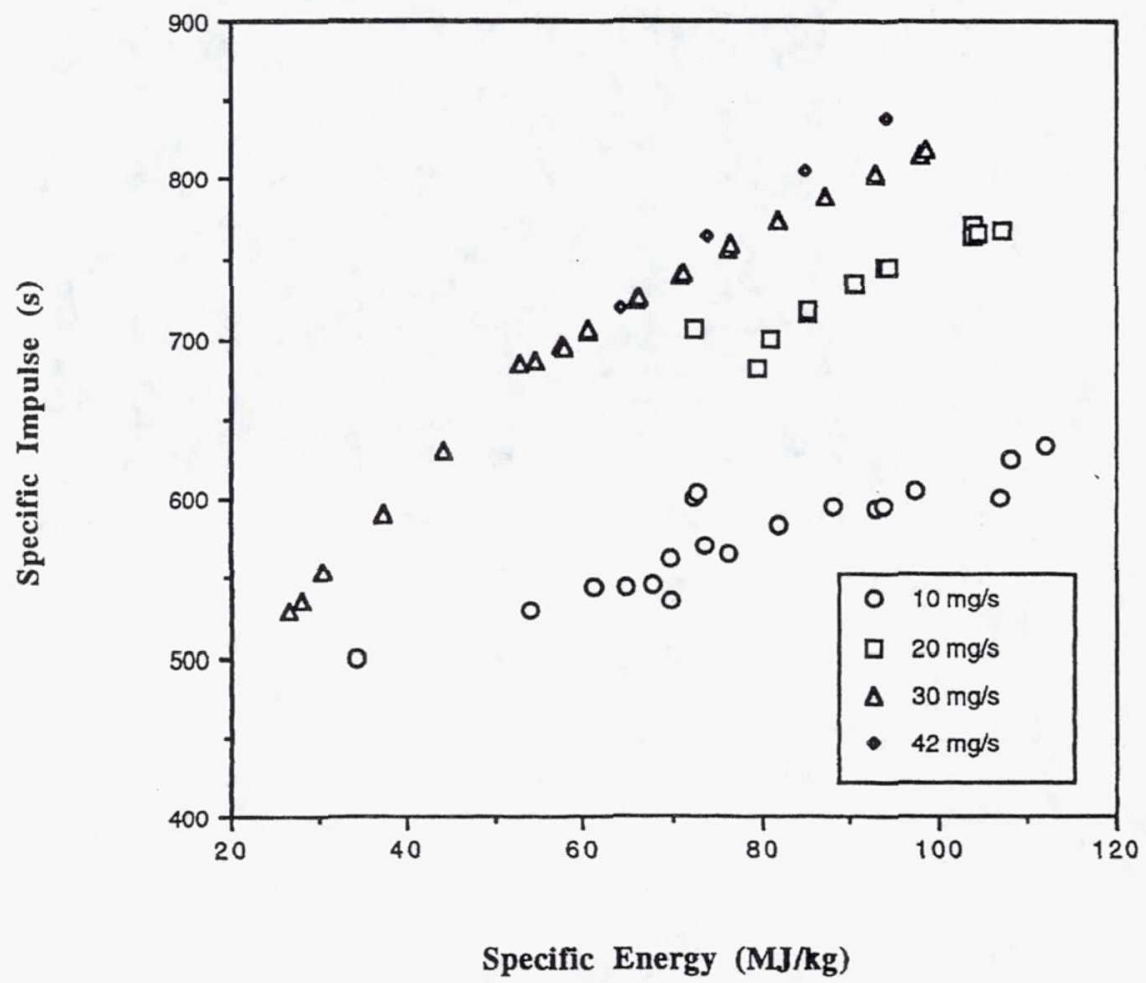

Figure 7.-Specific impulse versus specific energy. 


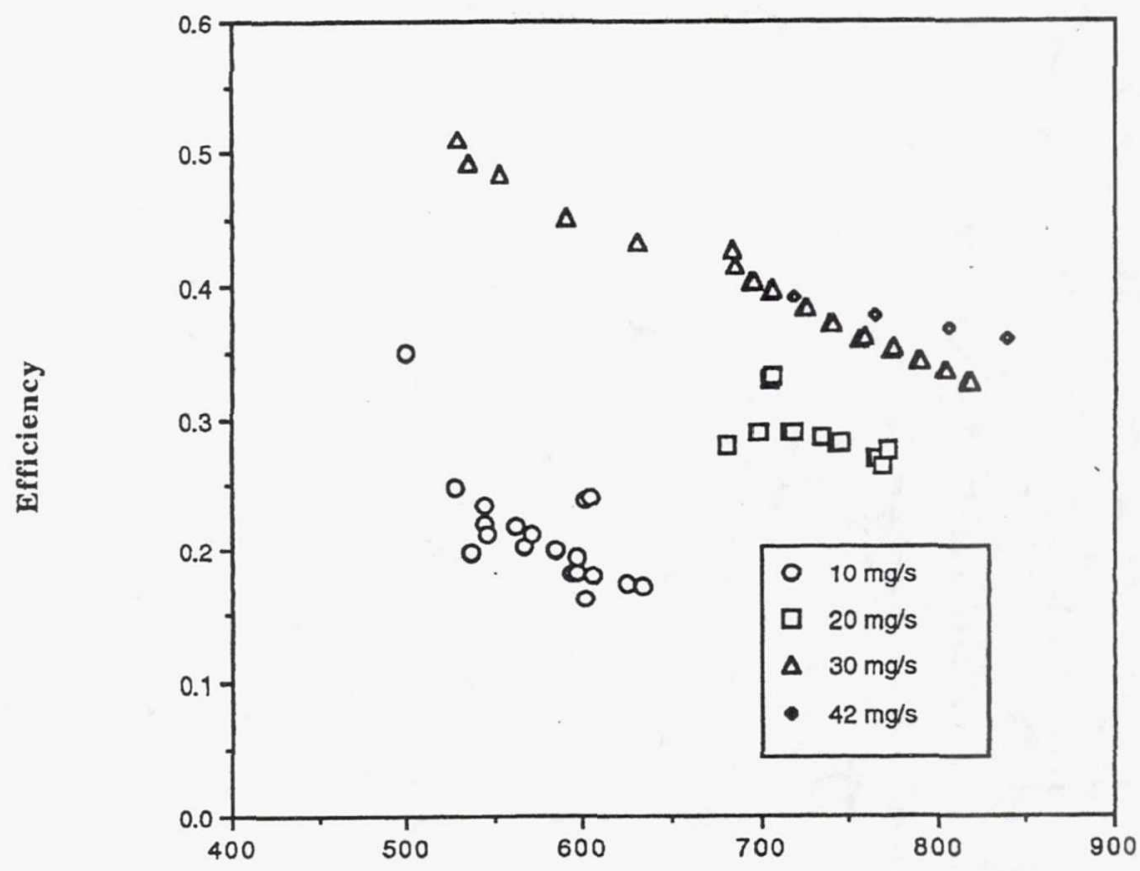

Specific Impulse (s)

Figure 8.-Efficiency versus specific impulse.

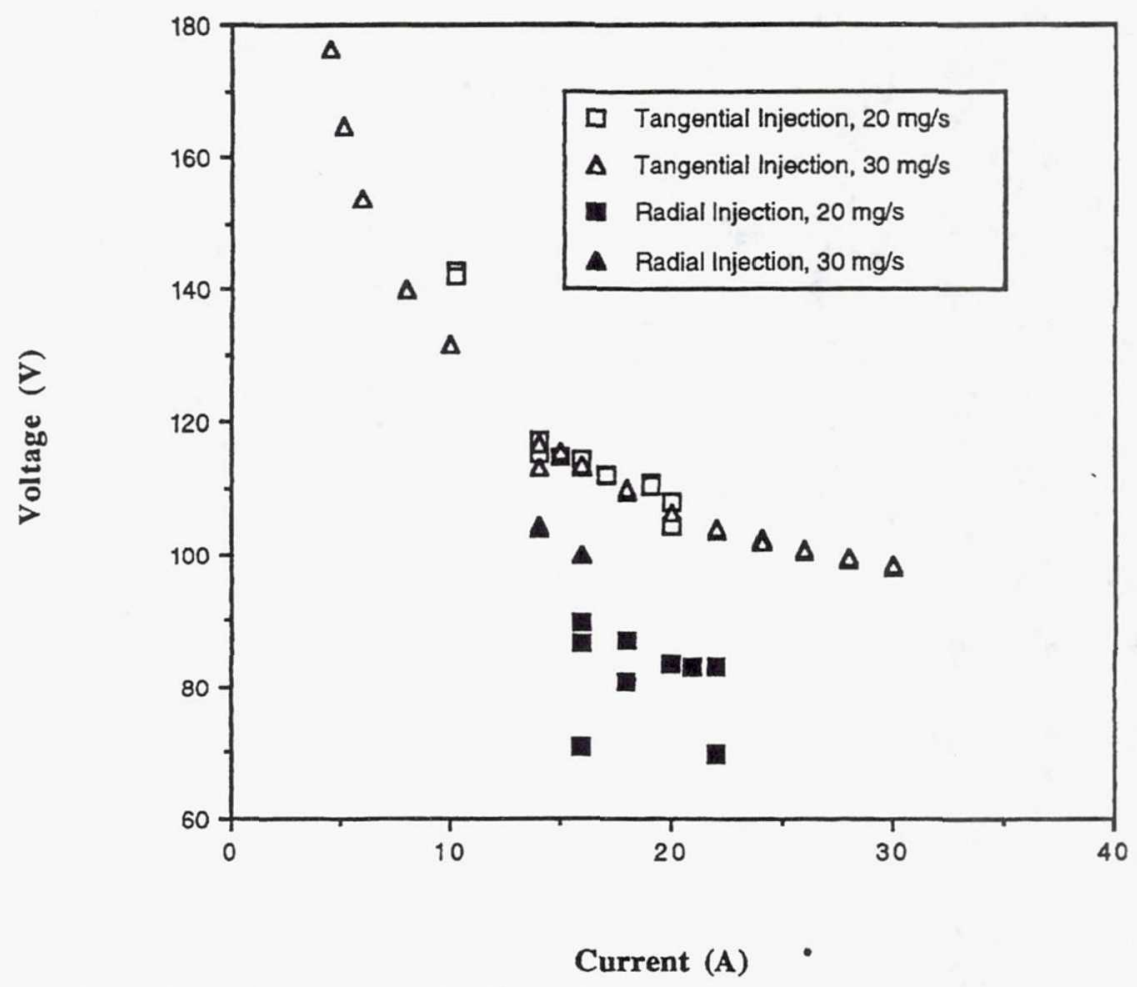

Figure 9.-Effects of propellant injection on voltage-current characteristic. 


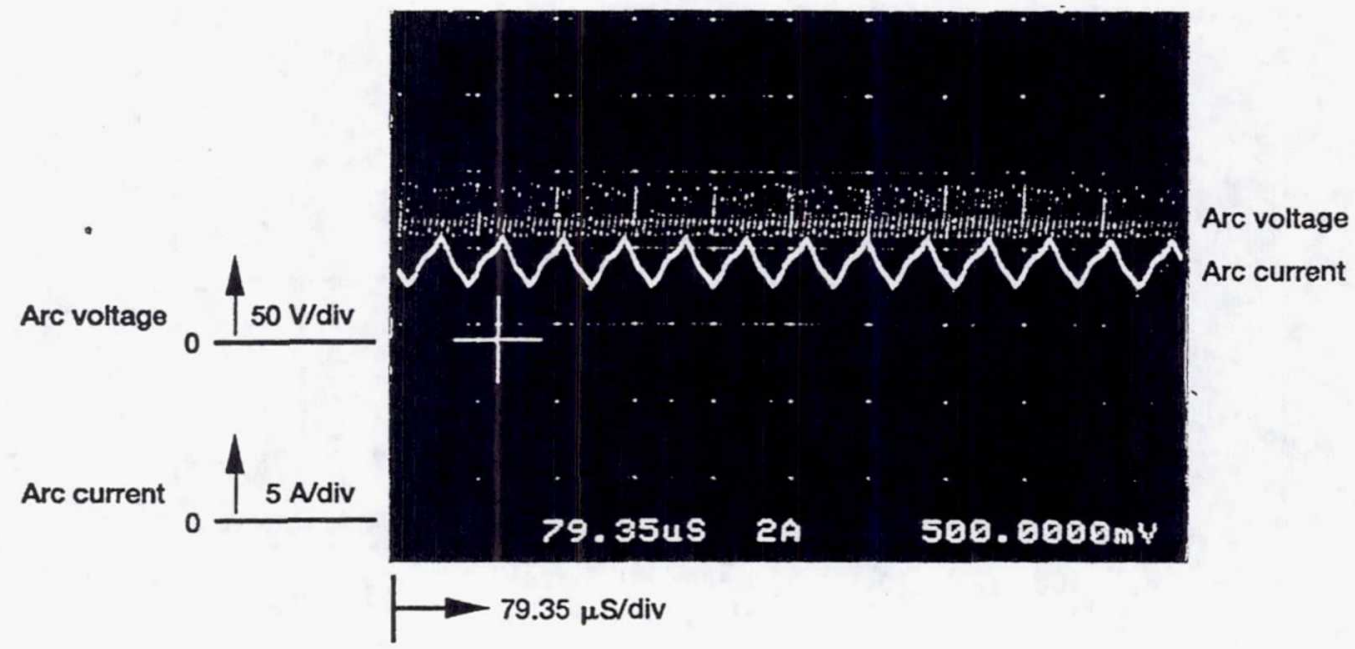

(a) Radial injection.

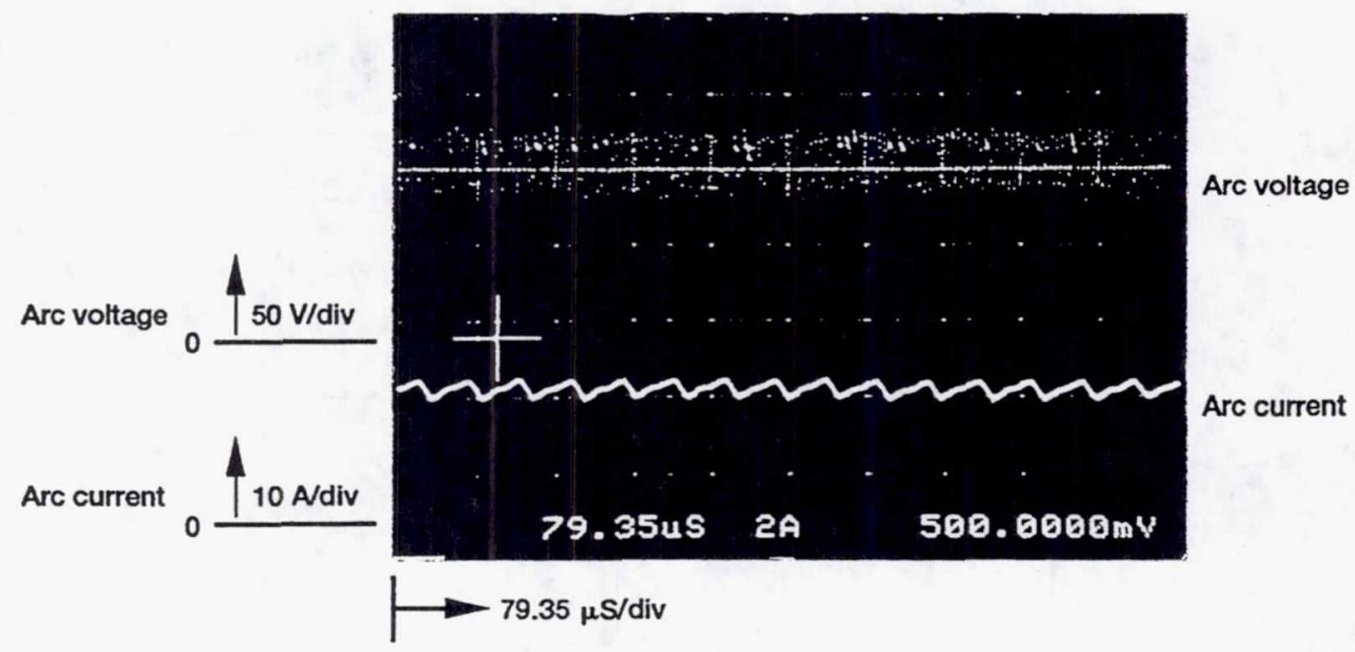

(b) Tangential injection.

Figure 10.-Oscilloscope traces showing effect of propellant injection on arc stability at $20 \mathrm{mg} / \mathrm{s}$ and 16 . 


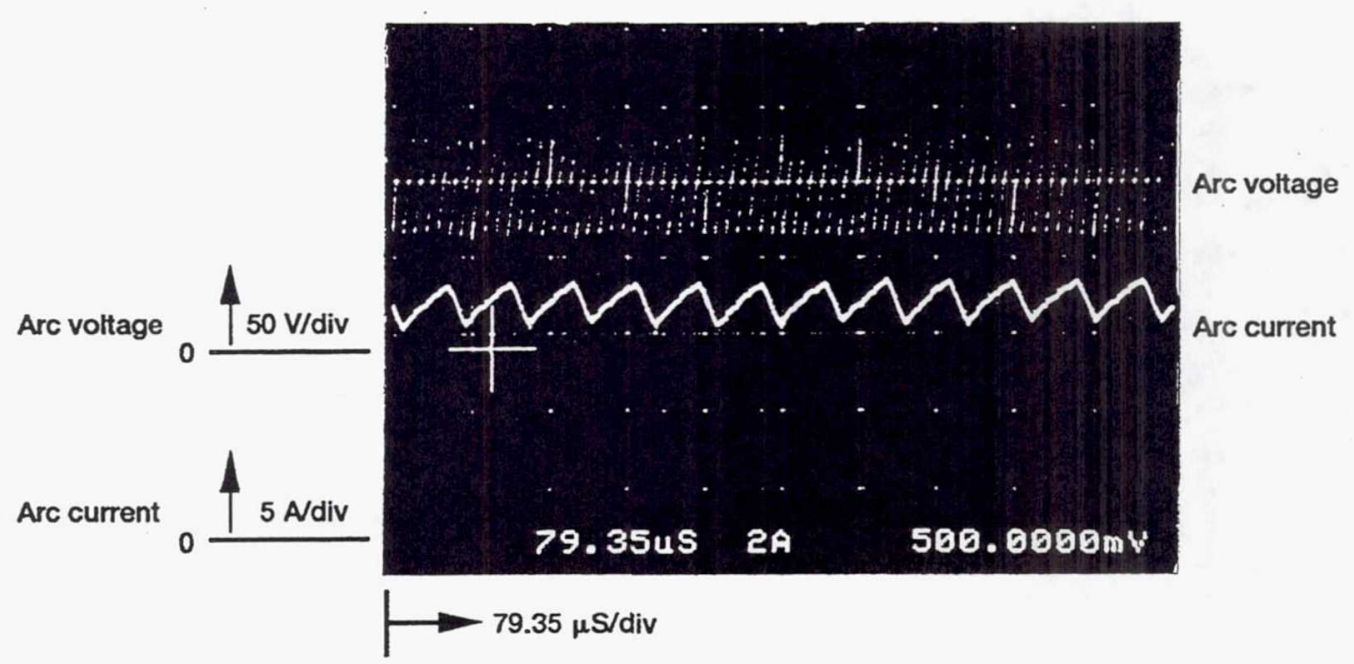

(a) Radial injection.

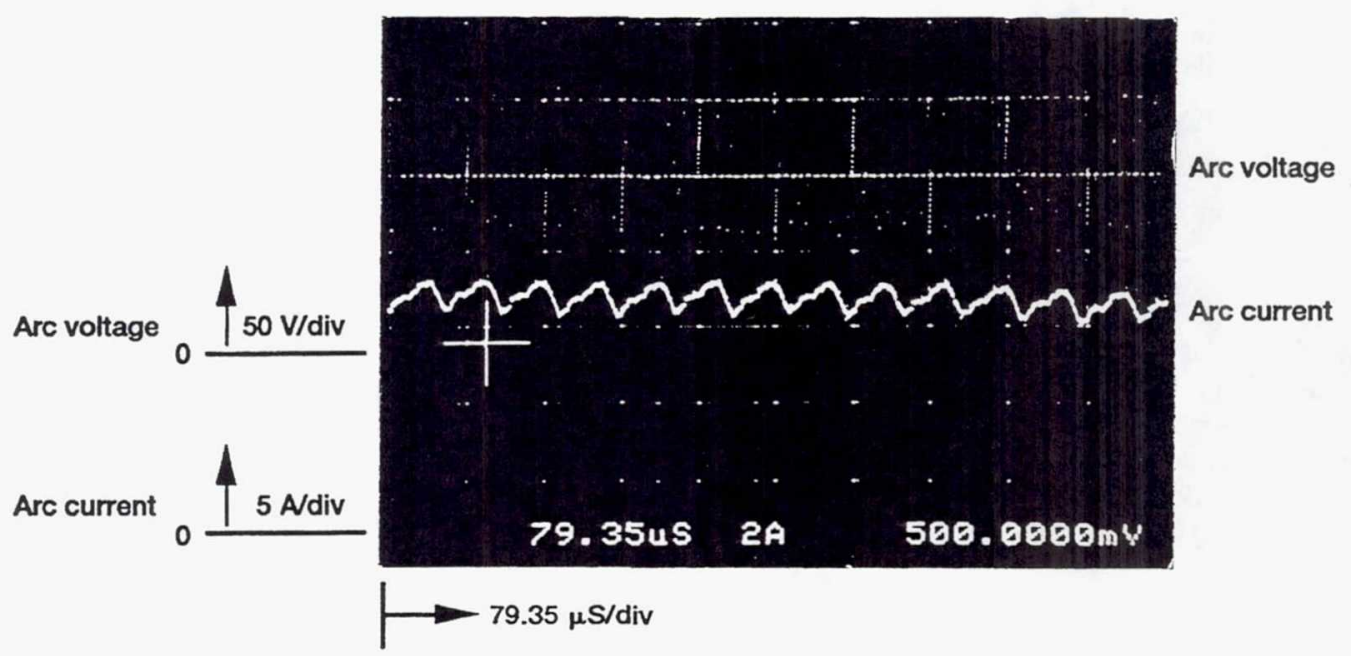

(b) Tangential injection.

Figure 11.-Oscilloscope traces showing effect of propellant injection on arc stability at $30 \mathrm{mg} / \mathrm{s}$ and 14A. 


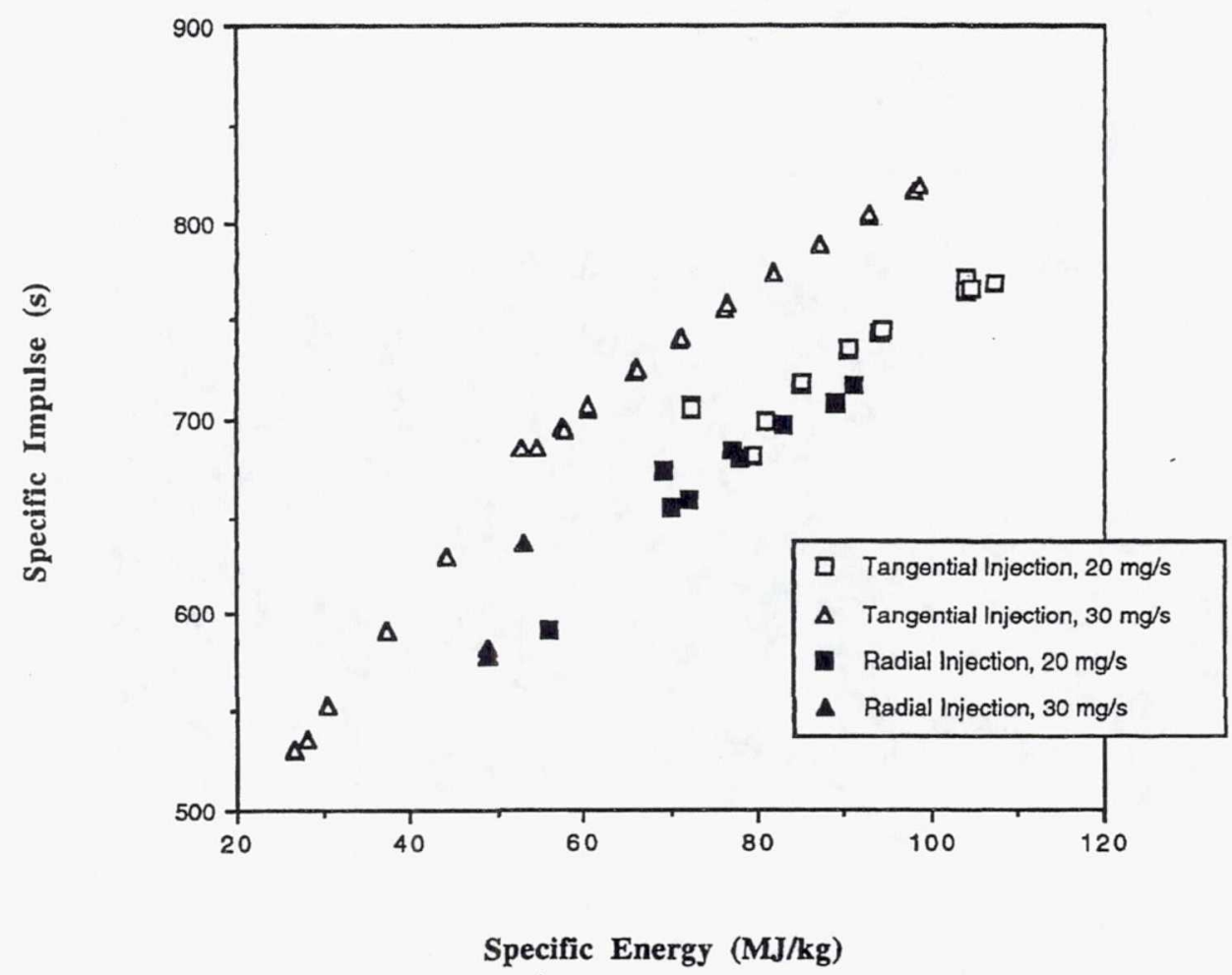

Figure 12.-Effects of propellant injection on specific impulse.

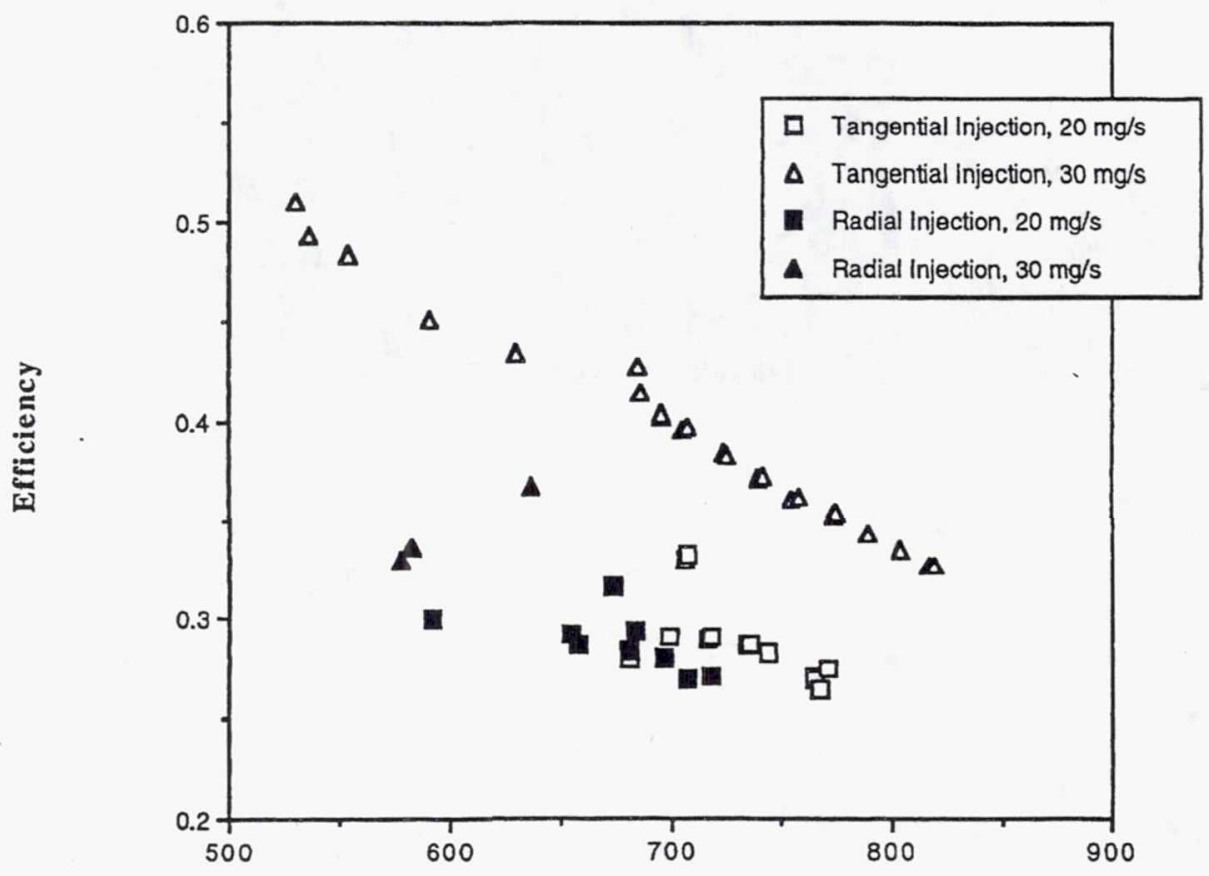

Specific Impulse (s)

Figure 13.-Efficiency versus specific impulse using different propellant injection methods. 


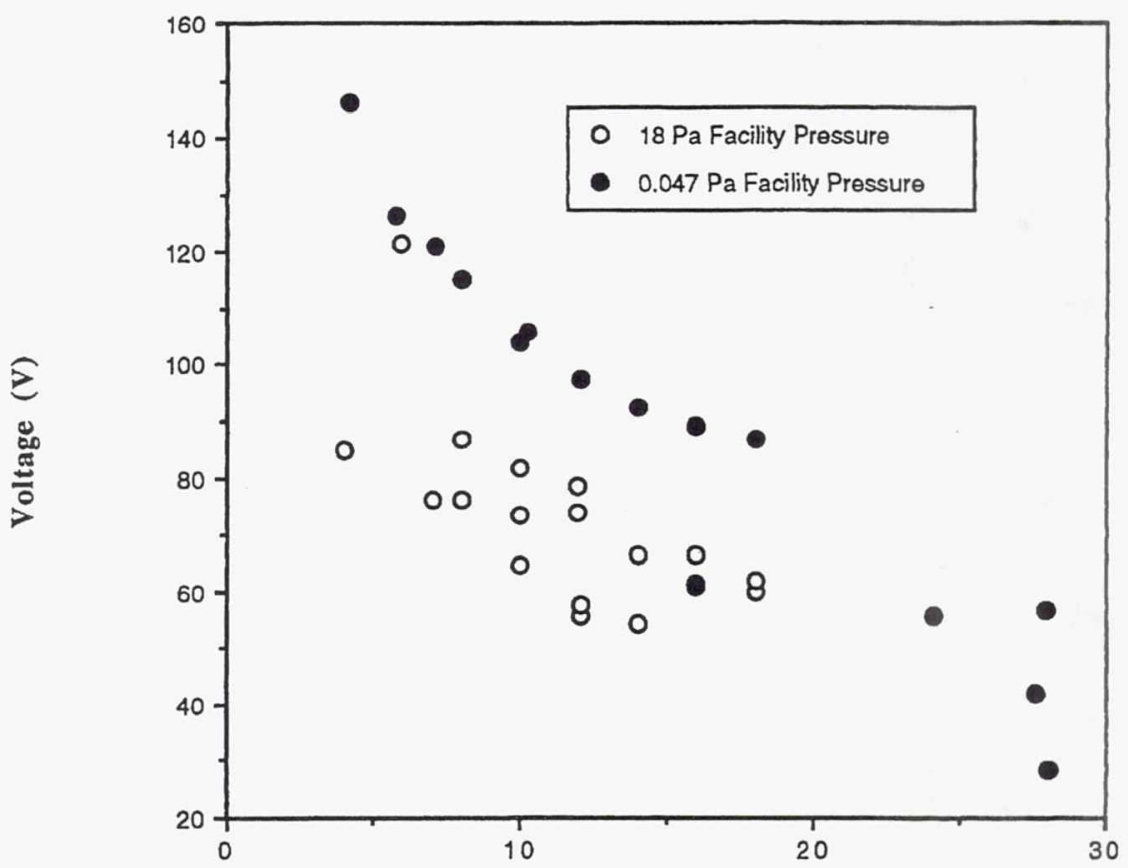

Current (A)

Figure 14.-Effects of facility background pressure on voltage-current characteristic at $10 \mathrm{mg} / \mathrm{s}$ propellant flow rate.

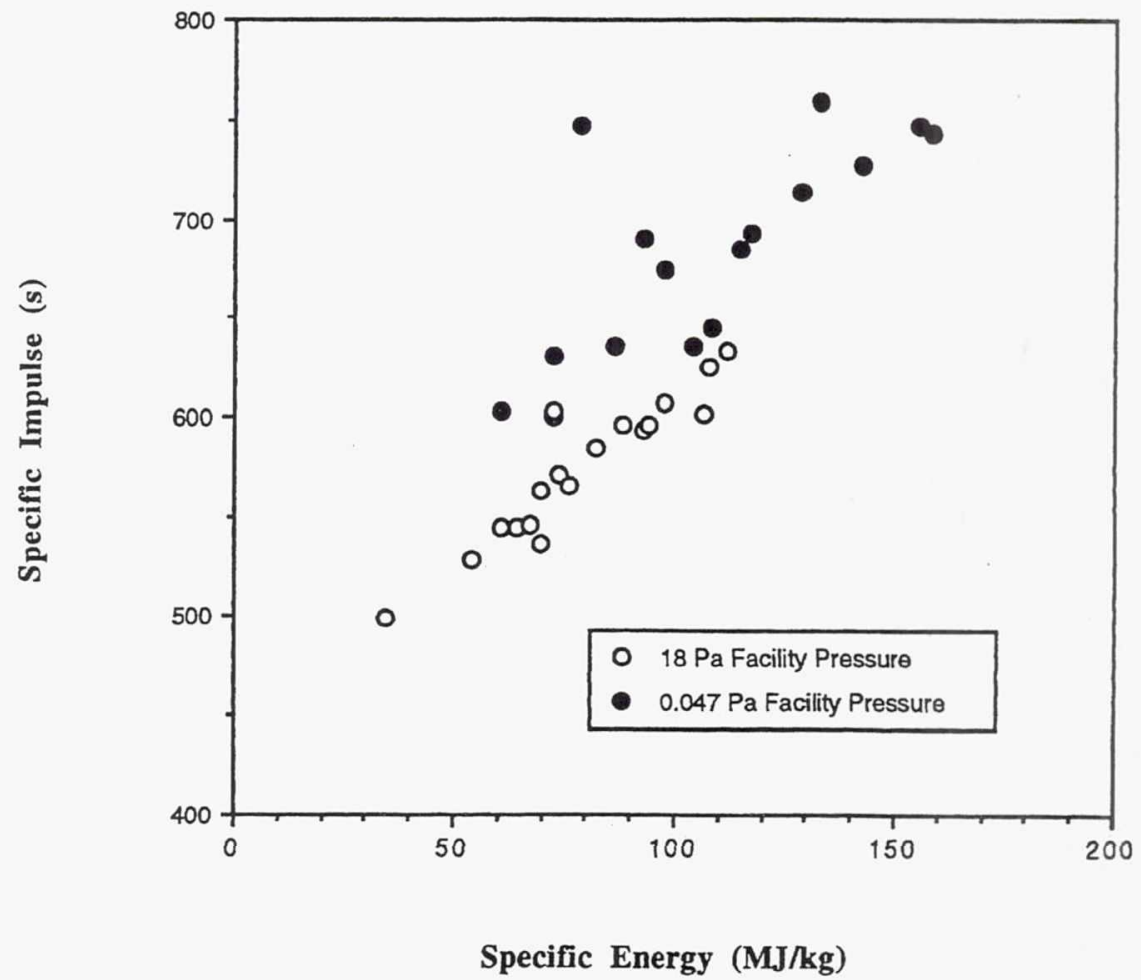

Figure 15.-Effects of facility background pressure on specific impulse at $10 \mathrm{mg} / \mathrm{s}$ propellant flow rate. 


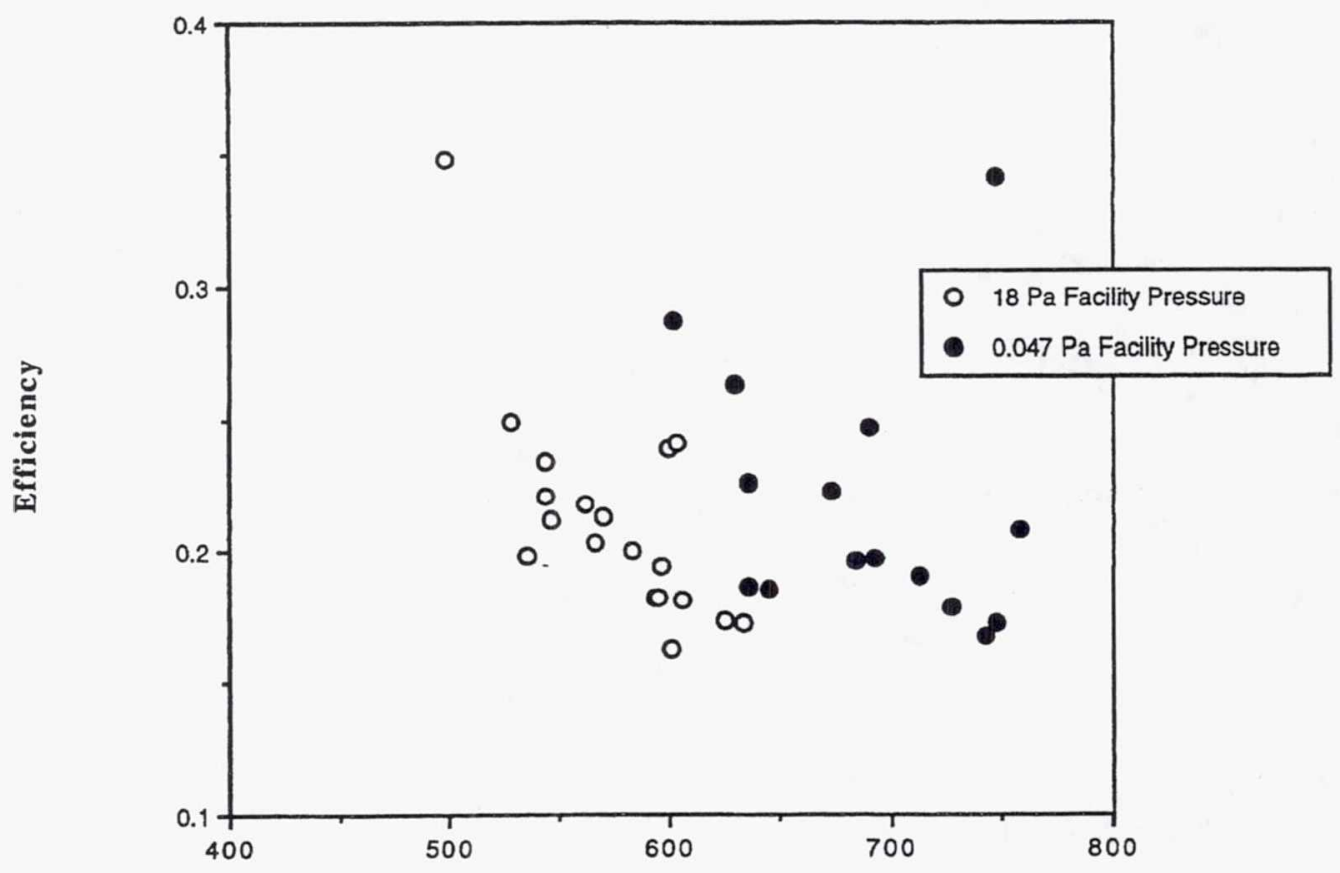

Specific Impulse (s)

Figure 16.-Effects of facility background pressure on efficiency-specific impulse curve at $10 \mathrm{mg} / \mathrm{s}$ propellant flow rate. 


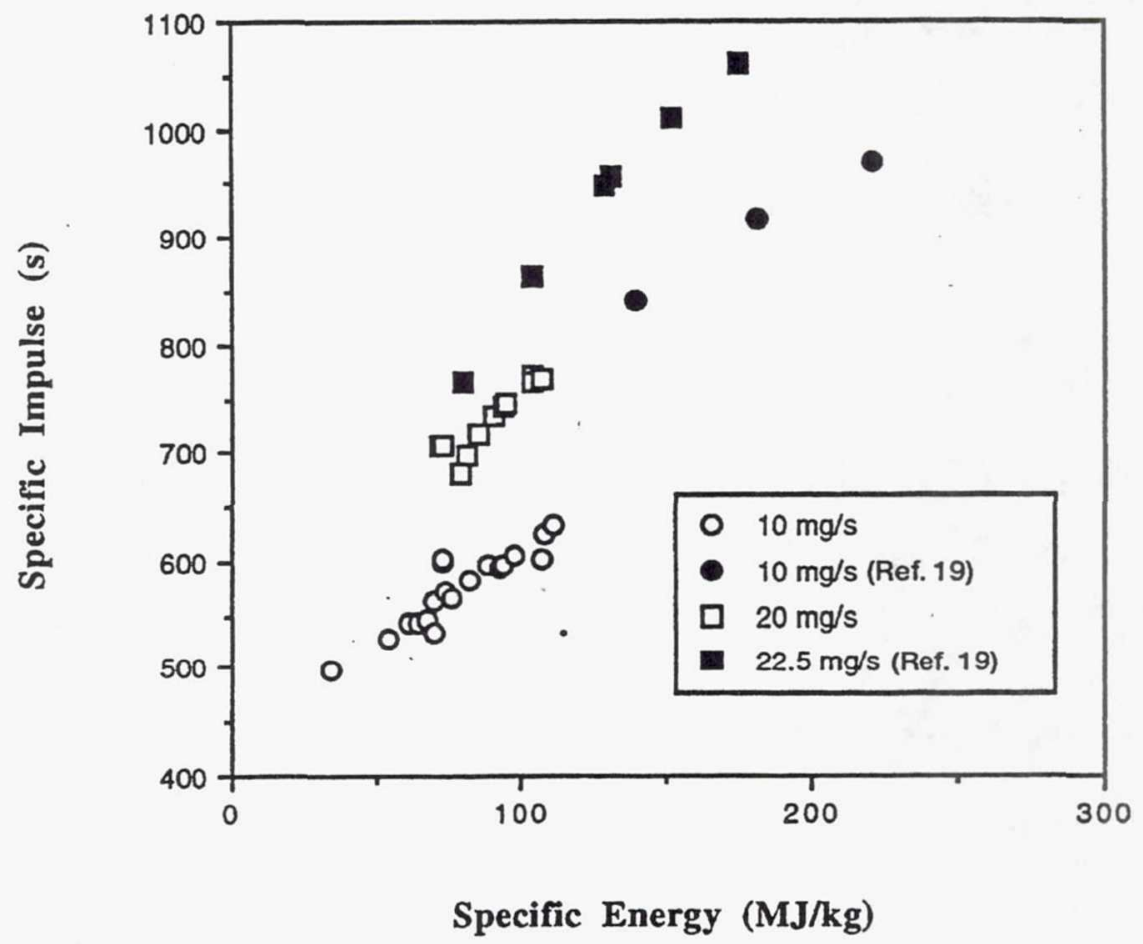

Figure 17.-Comparison between subsonic-and supersonic-arc-attachment thruster specific impulse versus specific energy curves.

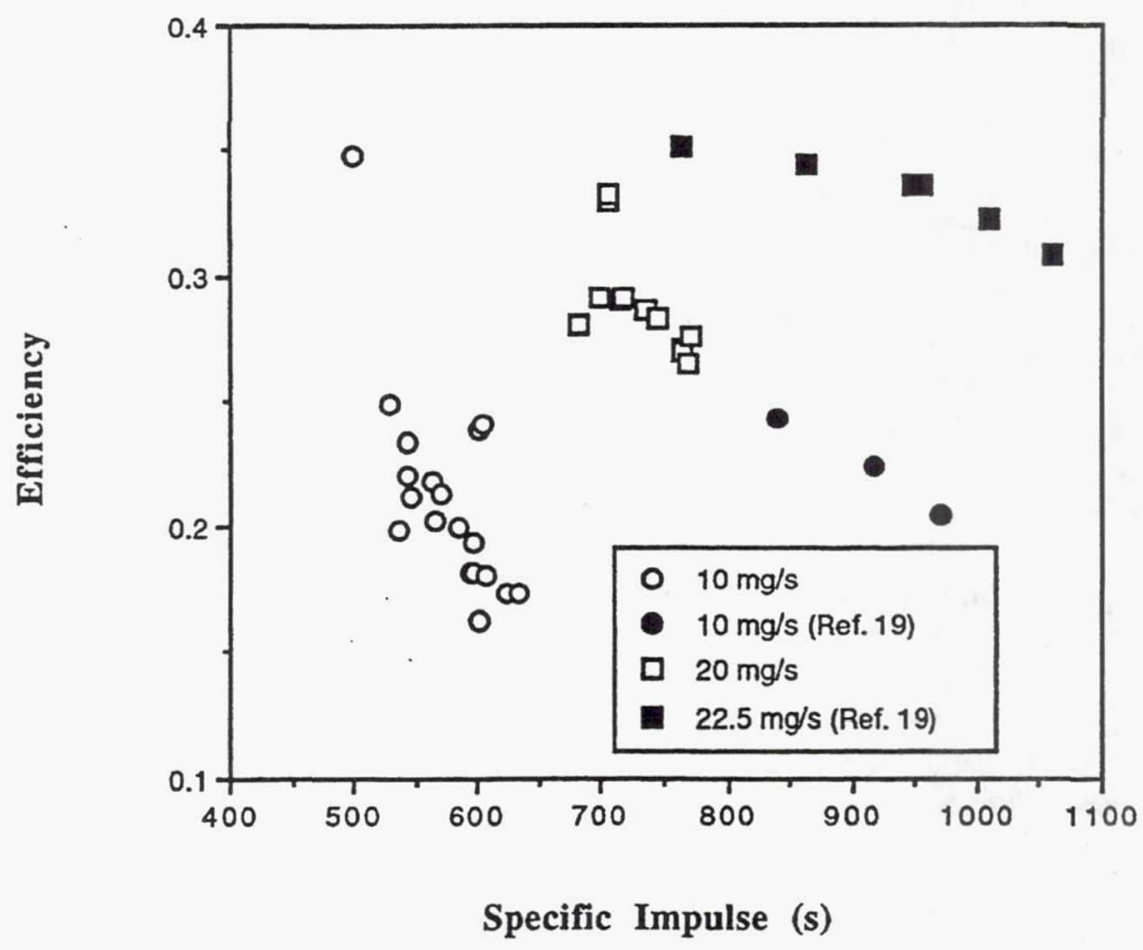

Figure 18.-Comparison between subsonic-and supersonic-arc-attachment thruster efficiency versus special impulse curves. 
Public reporting burden for this collection of information is estimated to average 1 hour per response, including the time for reviewing instructions, searching existing data sources, gathering and maintaining the data needed, and completing and reviewing the collection of information. Send comments regarding this burden estimate or any other aspect of this
collection of information, including suggestions for reducing this burden, to Washington Headquarters Services, Directorate for Information Operations and Reports, 1215 Jefferson Davis Highway, Suite 1204, Arlington, VA 22202-4302, and to the Office of Management and Budget, Paperwork Reduction Project (0704-0188), Washington, DC 20503.

\begin{tabular}{|l|l|l}
\hline 1. AGENCY USE ONLY (Leave blank) & $\begin{array}{c}\text { 2. REPORT DATE } \\
\text { June } 1993\end{array}$ & $\begin{array}{r}\text { 3. REPORT TYPE AND DATES COVERED } \\
\text { Technical Memorandum }\end{array}$
\end{tabular}

4. TITLE AND SUBTITLE 5. FUNDING NUMBERS

Performance of a Low-Power Subsonic-Arc-Attachment Arcjet Thruster

6. AUTHOR(S)

WU-506-42-31

John M. Sankovic and Darren H. Berns

7. PERFORMING ORGANIZATION NAME(S) AND ADDRESS(ES)

8. PERFORMING ORGANIZATION REPORT NUMBER

National Aeronautics and Space Administration.

Lewis Research Center

Cleveland, Ohio 44135-3191

E-7703

9. SPONSORING/MONITORING AGENCY NAME(S) AND ADDRESS(ES)

10. SPONSORING/MONITORING AGENCY REPORT NUMBER

National Aeronautics and Space Administration

Washington, D.C. 20546-0001

NASA TM-106244

AIAA-93-1898

11. SUPPLEMENTARY NOTES

Prepared for the 29th Joint Propulsion Conference and Exhibit cosponsored by the AIAA, SAE, ASME, and ASEE, Monterey, California, June 28-30, 1993. John M. Sankovic, NASA Lewis Research Center; and Darren H. Berns, University of Minnesota, Minneapolis, Minnesota 55455. Responsible person, John M. Sankovic, (216) 977-7429.

12a. DISTRIBUTION/AVAILABILITY STATEMENT 12b. DISTRIBUTION CODE

Unclassified - Unlimited

Subject Category 20

13. ABSTRACT (Maximum 200 words)

A subsonic-arc-attachment thruster design was scaled from a $30 \mathrm{~kW} 1960$ 's vintage thruster to operate at nominally $3 \mathrm{~kW}$. Performance measurements were obtained over a $1-4 \mathrm{~kW}$ power range using hydrogen as the propellant. Several modes of operation were identified and were characterized by varying degrees of voltage instability. A stability map was developed showing that the voltage oscillations were brought upon by elevated current or propellant levels. At a given specific energy level the specific impulse increased asymptotically with increased flow rates. Comparisons of performance were made between radial and tangential propellant injection. When the vortex flow was eliminated using radial injection, the operating voltages were lower at a given current, and the specific impulse and efficiency decreased. Tests were also conducted to determine the effects of background pressure on operation, and performance data were obtained at pressures of $0.047 \mathrm{~Pa}$ and $18 \mathrm{~Pa}$. For a given specific energy level, the performance increased with a decrease in facility background pressure. Lowering the background pressure also caused a dramatic change in the voltage-current characteristic and the voltage stability, a phenomenon not previously reported with conventional supersonic-arc-attachment thrusters.

\section{SUBJECT TERMS}

Electric Propulsion; Arcjet thrusters; Arc instabilities

15. NUMBER OF PAGES

28

\begin{tabular}{l|c|c|} 
7. SECURITY CLASSIFICATION \\
$\begin{array}{c}\text { OF REPORT } \\
\text { Unclassified }\end{array}$ & $\begin{array}{c}\text { 18. SECURITY CLASSIFICATION } \\
\text { OF THIS PAGE } \\
\text { Unclassified }\end{array}$ & $\begin{array}{c}\text { 19. SECURITY CLASSIFICATION } \\
\text { OF ABSTRACT } \\
\text { Unclassified }\end{array}$
\end{tabular}

